\title{
Article \\ Escherichia coli and Staphylococcus aureus Differentially Regulate Nrf2 Pathway in Bovine Mammary Epithelial Cells: Relation to Distinct Innate Immune Response
}

\author{
Yi-Tian Ying ${ }^{1,2,3}$, Jing Yang ${ }^{1,2,3}$, Xun Tan ${ }^{1,2,3, * \mathbb{C}}$, Rui Liu ${ }^{1}$, Ying Zhuang ${ }^{1,4}$, Jia-Xue Xu ${ }^{1,4}$ and Wei-Jia Ren ${ }^{1,2}$ \\ 1 Department of Veterinary Medicine, Zhejiang University, Yuhangtang Road 866, Hangzhou 310058, China; \\ yingyitian@zju.edu.cn (Y.-T.Y.); 21917098@zju.edu.cn (J.Y.); 3170100083@zju.edu.cn (R.L.); \\ 22017117@zju.edu.cn (Y.Z.); 22117114@zju.edu.cn (J.-X.X.); 22017103@zju.edu.cn (W.-J.R.) \\ 2 Veterinary Medical Center, Zhejiang University, Yuhangtang Road 866, Hangzhou 310058, China \\ 3 Institute of Preventive Veterinary Sciences, Yuhangtang Road 866, Hangzhou 310058, China \\ 4 Hainan Institute of Zhejiang University, Yazhou Bay Science and Technology City, Sanya 572025, China \\ * Correspondence: tanxun@zju.edu.cn; Tel.: +86-571-8898-2393
}

check for updates

Citation: Ying, Y.-T.; Yang, J.; Tan, X.; Liu, R.; Zhuang, Y.; Xu, J.-X.; Ren,

W.-J. Escherichia coli and

Staphylococcus aureus Differentially Regulate Nrf2 Pathway in Bovine Mammary Epithelial Cells: Relation to Distinct Innate Immune Response. Cells 2021, 10, 3426. https:/ / doi.org/10.3390/cells10123426

Academic Editor: Bernhard Ryffel

Received: 20 October 2021

Accepted: 2 December 2021

Published: 6 December 2021

Publisher's Note: MDPI stays neutral with regard to jurisdictional claims in published maps and institutional affiliations.

Copyright: (c) 2021 by the authors. Licensee MDPI, Basel, Switzerland. This article is an open access article distributed under the terms and conditions of the Creative Commons Attribution (CC BY) license (https:/ / creativecommons.org/licenses/by/ $4.0 /)$.

\begin{abstract}
Escherichia coli and Staphylococcus aureus are major mastitis causing pathogens in dairy cattle but elicit distinct immune and an inflammatory response in the udder. However, the host determinants responsible for this difference remains largely unknown. Our initial studies focused on the global transcriptomic response of primary bovine mammary epithelial cells (pbMECs) to heat-killed E. coli and S. aureus. RNA-sequencing transcriptome analysis demonstrates a significant difference in expression profiles induced by E. coli compared with S. aureus. A major differential response was the activation of innate immune response by E. coli, but not by S. aureus. Interestingly, E. coli stimulation increased transcript abundance of several genes downstream of Nrf2 (nuclear factor erythroid 2-related factor 2) that were enriched in gene sets with a focus on metabolism and immune system. However, none of these genes was dysregulated by S. aureus. Western blot analysis confirms that $S$. aureus impairs Nrf2 activation as compared to E. coli. Using Nrf2-knockdown cells we demonstrate that $\mathrm{Nrf} 2$ is necessary for bpMECs to mount an effective innate defensive response. In support of this notion, nuclear Nrf2 overexpression augmented S. aureus-stimulated inflammatory response. We also show that, unlike E. coli, S. aureus disrupts the non-canonical p62/SQSTM1-Keap1 pathway responsible for Nrf2 activation through inhibiting p62/SQSTM1 phosphorylation at S349. Collectively, our findings provide important insights into the contribution of the Nrf2 pathway to the pathogen-species specific immune response in bovine mammary epithelial cells and raise a possibility that impairment of Nrf2 activation contributes to, at least in part, the weak inflammatory response in S. aureus mastitis.
\end{abstract}

Keywords: bovine; mastitis; mammary epithelia cells; Nrf2; Escherichia coli; Staphylococcus aureus

\section{Introduction}

Mastitis (inflammation of the mammary gland and udder tissue) is the most prevalent disease in dairy cows and is a major cause of economic losses in dairy farms worldwide [1]. A wide spectrum of pathogenic agents has been implicated in the etiology of mastitis, of which Escherichia coli and Staphylococcus aureus are the most commonly involved gramnegative and gram-positive bacteria, respectively [2-5]. It is well known that these two pathogens elicit a distinct inflammatory response in the bovine udder. E. coli infection leads very often to severe inflammation associated with rapid onset of clinical signs followed by fast clearance of the infection [6], although some E. coli strains have been reported to cause chronic infection [7]. On the contrary, intramammary infections with S. aureus typically cause a much weaker innate immune response, resulting in lifelong pathogen persistence with severe tissue damage $[8,9]$. Infected cows routinely shed large numbers of 
S. aureus into their milk, which can lead to foodborne poisoning in humans [10], posing a threat to human health. Moreover, cows have been identified as the main source of novel human-pathogenic S. aureus clones [11], underscoring their zoonotic potential. Although extensively studied, the interaction between $S$. aureus and the host response remains largely unclear.

The nuclear factor erythroid 2-related factor 2 ( Nrf2, encoded by Nfe2l2) is a stress responsive transcription factor, which is well known for its function of cytoprotection against electrophilic and oxidative stress [12]. Nrf2 activity is suppressed under homeostatic conditions through Keap1 (Kelch-like erythroid cell-derived protein with CNC homology-associated protein 1)-mediated ubiquitination-proteasomal degradation. In the presence of electrophiles or oxidants, Nrf2 disassociates from Keap1, resulting in Nrf2 stabilization and nuclear translocation/accumulation, followed by transcriptional activation of a battery of Nrf2 target genes encoding detoxifying enzymes and antioxidant proteins, such as NAD(P)H:quinone oxidoreductase (NQO)-1, glutamate-cysteine ligase, modifier subunit (GCLM) and superoxide dismutase (SOD) [13,14]. Besides mediating a stress-stimulated induction of antioxidant and detoxification genes, Nrf2 is recognized as a master regulator of tissue damage control to infection [15]. In addition, it has been shown that Nrf2 activation limits an excessive inflammatory response [16,17]. However, there is also evidence showing that Nrf2 promotes, rather than restrains, the immune response [18]. So far, little is known about the Nrf2 pathways in the pathophysiology of bovine mastitis.

Bovine mammary epithelial cells (MECs) lining the inner surface of the mammary gland constitute an important part of innate immunity. MECs are the most abundant cell type of the lactating udder [19]. These cells are capable of responding to bacterial intrusion, and are regarded as active contributors to immune and inflammatory responses of the mammary gland [20-23]. Furthermore, recent evidence shows the pathogen-specific immune response of MECs, but not of the resident immune cells (e.g., macrophages), which reflects many aspects of the pathogen species-specific characteristics of in vivo infected udders [20,24], leading to the suggestion that the respective response of MECs determines the pathogen species-specific immune response of mastitis [25].

In this study, we compared the transcriptome profile of primary cultures of bovine MECs (pbMECs) stimulated with heat-killed mastitis pathogens E. coli and S. aureus. We found that pbMECs responded to $E$. coli, but not to $S$. aureus, with transcriptional activation of several Nrf2 target genes. We further explored the mechanisms by which $E$. coli cause Nrf2 activation, whereas $S$. aureus do not, by focusing on the well characterized canonical redox-Keap1-Nrf2 [12,26] and non-canonical p62/sequestosome 1 (SQSTM1)-Keap1-Nrf2 pathways [27]. In addition, the role of Nrf2 in the immune response of bovine mammary epithelium to mastitis pathogens was investigated.

\section{Materials and Methods}

\subsection{Cell Culture and Mastitis Pathogens}

pbMECs were isolated from 3 healthy first lactating Chinese Holstein heifers using procedures as previously described [28]. The procedure was approved by the Animal Care and Use Committee guidelines in Zhejiang University (approval number ZJU20160379). The cows had been culled in the normal culling regime. Cells were cultured in low-glucose Dulbecco's modified Eagle's medium (DMEM) containing 10\% fetal calf serum (FCS), insulin $(1 \mu \mathrm{g} / \mathrm{mL})$, amphotericin B $(10 \mu \mathrm{g} / \mathrm{mL}$, Invitrogen, Carlsbad, CA, USA), tylosin tartrate $(50 \mu \mathrm{g} / \mathrm{mL})$ and penicillin-streptomycin $(200 \mu \mathrm{g} / \mathrm{mL})$ at $37^{\circ} \mathrm{C}$ in a humidified atmosphere of $5 \% \mathrm{CO}_{2}$. After $2 \mathrm{~h}, \mathrm{DMEM}$ was replaced by fresh medium and the medium was then changed every 2 days. The primary cell cultures were passaged at $\sim 80 \%$ confluence. Fibroblasts in the culture were removed as previously described [29]. The pure pbMECs after passages 4 were used for subsequent experiments. The E. coli and S. aureus used in this work were isolated from the milk sample of bovine mastitis. Identification of bacterial species was performed by means of culture, Gram staining and 16S rRNA gene sequencing (data not shown). The culturing of the bacteria and their use to challenge 
pbMECs were conducted as described previously [30]. E. coli and S. aureus inactivation was performed at $70{ }^{\circ} \mathrm{C}$ and $85^{\circ} \mathrm{C}$, respectively, for $30 \mathrm{~min}$. Viability loss of pathogens after heat treatment was tested on blood agar plates.

\subsection{High throughout Sequencing}

pbMECs were stimulated with heat-inactivated E. coli or S. aureus at $1 \times 10^{7}$ particles/mL for $24 \mathrm{~h}$ [30]. Total RNA was extracted using TRIzol reagent (Takara Biomedical Technology, Dalian, China) following the manufacturer's protocol without modification. Sequencing library of each sample was constructed with $1 \mu \mathrm{g}$ total RNA using NEBNext UltraTM RNA Library Prep Kit (NEB, llumina Inc., San Diego, CA, USA). The proper length of cDNA in each library was ensured by running the DNA 1000 assay on the Agilent 2100 Bioanalyzer. The library preparations were sequenced on an Illumina Hiseq Xten platform and $150 \mathrm{bp}$ paired-end reads were generated. After quality assessment of the raw reads using FastQC (version 0.10.1, Babraham Institute Bioinformatics Group, Cambridge, UK), adapter sequences and sequences of low quality (Sanger base quality < 20) were trimmed. The clean reads of each sample were then mapped to the Bos Taurus reference genome (assembly ARS-UCD1.2) using TopHat2 (version 2.0.9, Johns Hopkins University Center for Computational Biology, Baltimore, MD, USA) with default parameters. Only reads with a perfect match or one mismatch were further analyzed and annotated. Analysis of differential expression genes (DEGs) between groups was conducted using the DESeq R package (version 1.10.1, Bioconductor, Boston, MA, USA). The resulting $p$ values were adjusted using the Benjamini and Hochberg's approach to control the false discovery rate (FDR). The genes with absolute Log2 fold change $(\log 2 \mathrm{FC})>0.1$ and FDR $<0.05$ were considered as significant DEGs between groups. The DEGs was then subjected Gene ontology (GO) analysis, Kyoto Encyclopedia of Genes and Genomes (KEGG) pathway and Reactome pathway enrichment analysis.

\subsection{Real-Time Quantitative PCR}

Total RNA was extracted using TRIzol reagent (Takara Biomedical Technology, Dalian, China). First strand cDNA synthesis was performed using PrimeScript RT reagent Kit with genomic DNA Eraser (Takara Biomedical Technology, Dalian, China) in a reaction containing $1 \mu \mathrm{g}$ RNA according to the supplier's instruction. Intron-spanning primer sets were designed using the Primer-BLAST program (http:/ / www.ncbi.nlm.nih.gov / tools/primer-blast, 20 March 2019) and are presented in Table S1. Primer amplification efficiencies were determined by real-time quantitative PCR (qPCR) using the equation E = $10^{[-1 / \text { slope }]}$ - 1 . PCR was performed using Roche LightCycler 480 with SYBR Green Realtime PCR Master Mix Plus (Vazyme, Nanjing, China). Data were normalized to reference genes RPL19 and PGK1 by using an efficiency corrected method of Pfaffl [31].

\subsection{Immunoblot Analysis}

Cells were washed twice with phosphate-buffered saline (PBS) and lysed in radioimmunoprecipitation assay buffer (RIPA) (FDbio Science, Hangzhou, China) containing protease inhibitors and phosphatase inhibitors. Samples were boiled at $95{ }^{\circ} \mathrm{C}$ for 5 min to denature proteins. Proteins were separated by using a sodium dodecyl sulfate (SDS)-10\% polyacrylamide gel electrophoresis (PAGE) Fast Preparation Kit (FDbio Science, Hangzhou, China) and electroblotted onto polyvinylidene difluoride (PVDF) membranes (Millipore, Bedford, MA, USA). After being blocked for $2 \mathrm{~h}$ in Tris-buffered saline and Tween 20 (TBST) containing 5\% non-fat milk, membranes were washed three times in TBST and probed with primary antibodies against Keap1 (Proteintech, Wuhan, China), Nrf2 (R1312-8, HUABIO, Hangzhou, China), pIкB $\alpha$ (Santa Cruz Biotechnology, Shanghai, China), phospho-NF- $\mathrm{B}$ p65 (Ser536) (Abcam, Cambridge, UK), GADPH (FDbio Science, Hangzhou, China), Histone (Santa Cruz Biotechnology, Shanghai, China), SQSTM1/p62 (Affinity Biosciences, Changzhou, China), pSer349-SQSTM1/p62 (Affinity Biosciences, Changzhou, China), GFP (HUABIO, Hangzhou, China) and $\beta$-actin (Cell Signaling Technology, Danvers, MA, 
USA). The primary antibody was detected using appropriate horseradish peroxidase (HRP)-conjugated secondary antibody. Immunoreactive bands were visualized by electrochemiluminescent (ECL) (FDbio Science, Hangzhou, China).

\subsection{Nuclear and Cytosolic Fractionation}

Cells were washed 3 times with PBS before nuclear and cytosolic fractionation. Nuclear and cytoplasmic fractionation were conducted using the Nuclear-Cytosol Extraction Kit (FDbio Science, Hangzhou, China) according to the manufacturer's instructions. Each separated protein was analyzed by Western blot analysis.

\subsection{Immunofluorescent Staining}

pbMECs were seeded on 24-well plates at $1 \times 10^{4}$ cells/well. After treatments, the cells were fixed with $4 \%$ paraformaldehyde followed by permeabilization in $0.25 \%$ Triton $\mathrm{X}-100$ in PBS. After incubated with 5\% bovine serum albumin (BSA), the cells were probed with a primary antibody against Nrf2 (1:1000, HUABIO, Hangzhou, China) overnight at $4{ }^{\circ} \mathrm{C}$. Then the cells were incubated with an Alexa Fluor 594-conjugated secondary antibody (1:1000, Abcam, Cambridge, UK). Cells nuclei was visualized with 4,6-diamidino2-phenyindole (DAPI, Sigma-Aldrich, St. Louis, MO, USA). Cytosolic and nuclear Nrf2 location was examined using a fluorescence microscope (Nikon Eclipse Ti-S, Tokyo, Japan).

\subsection{Measurement of ROS Levels}

ROS was measured using 2', $7^{\prime}$-dichlorofluorescein diacetate (DCF-DA, Sigma-Aldrich, Sigma-Aldrich, St. Louis, MO, USA). Briefly, pbMECs were incubated with LPS $(10 \mu \mathrm{g} / \mathrm{mL})$ or S. aureus $\left(1 \times 10^{7}\right.$ particles $\left./ \mathrm{mL}\right)$ for $6-12 \mathrm{~h}$. After washing in PBS, the cells were incubated in $20 \mu \mathrm{M}$ DCF-DA in serum-free medium for $15 \mathrm{~min}$ in the dark at $37^{\circ} \mathrm{C} .2$, $7-$ dichlorofluorescein (DCF) fluorescence was measured at $480 \mathrm{~nm} / 520 \mathrm{~nm}$ by flow cytometry (BD, FACS Verse, San Jose, CA, USA).

\subsection{Introduction of Small Interfering RNA against Nrf2}

Small interfering RNAs (siRNAs) were designed and synthesized by GenePharma (Shanghai, China). Cells were transfected with target-specific or nontargeting negative control siRNAs using Lipofectamine 2000 (Invitrogen, Waltham, MA, USA) according to the manufacturer's instructions. The sequence of Nrf2 siRNA is $5^{\prime}$-GCAAUUCAACGAGGCUC AATT- $3^{\prime}$ (sense) and 5'-UUGAGCCUCGUUGAAUUGCTT-3' (antisense). The sequence of negative control siRNA is $5^{\prime}$ - UUCUCCGAACGUGUCACGUTT - $3^{\prime}$ (sense) and 5'ACGUGACACGUUCGGAGAATT-3' (antisense). The final concentration of the siRNAs was $20 \mathrm{nmol} / \mathrm{L}$. Knockdown efficiencies were determined by qPCR and Western blot analysis.

\subsection{Determination of Cell Viability}

Cell viability was determined using the methyl thiazolyl tetrazolium (MTT) assay. Briefly, cells were incubated with $10 \mathrm{mg} / \mathrm{mL}$ MTT (Sigma-Aldrich, Saint Louis, MO, USA) at $37^{\circ} \mathrm{C}$ for $4 \mathrm{~h}$. Dimethyl sulfoxide (DMSO) was added to culture medium to dissolve the formazan crystals for $15 \mathrm{~min}$ in the dark. The optical density (OD) of the solubilized product was measured at $540 \mathrm{~nm}$. Cell viability was plotted as the mean OD540 value of six replicates.

\subsection{Plasmids Construct and Transient Transfection}

The full-length open reading frame (ORF) of bovine p62/SQSTM1 cDNAs with an optimal Kozak consensus sequence just before the in-frame first ATG was cloned into the eukaryotic expression vectors pCMV-N-Myc. For the construct of $3 \times$ NLS-Nrf2 expression plasmid, a DNA fragment encoding 3 repeat $(3 \times)$ nuclear localization signal (NLS) polypeptide PKKKRKV from the SV 40 large T antigen was subcloned into a XhoI/HindIII digested pEGFP-C3 plasmid, followed by inserting the Nrf2 ORF cDNA into the HindIII/ BamHI digested pEGFP-NLS plasmid. The constructs were confirmed by DNA sequencing. Ex- 
pression plasmid DNAs were transfected into pbMECs using the Lipo8000 (Beyotime Biotech, Nanjing, China) according to the manufacturer's instructions. Cells were used for further analysis at 24 or $48 \mathrm{~h}$ after transfection.

\subsection{Statistical Analysis}

Data are presented as mean \pm standard deviation (s.d.). Statistical analysis was performed with the SPSS software version 22 (IBM Corp, Armonk, NY, USA). The significance of the differences between groups was analyzed using a one-way ANOVA followed by LSD, or a nonparametric Mann-Whitney $U$ test, as appropriate. A value of $p<0.05$ was taken as the threshold level for statistical significance.

\section{Results}

\subsection{Gene Expression Profiles in E. coli- and S. aureus-Challenged pbMECs}

To characterize the modulatory effect of E. coli and $S$. aureus on the gene expression profiles, pbMECs were stimulated with heat-killed $E$. coli or $S$. aureus for $24 \mathrm{~h}$. Unstimulated cells were served as controls. E. coli particle treatment induced a large number of gene expression changes. We identified 1478 (8.5\% of 17297 genes) differentially expressed genes (DEGs) from the transcriptome profiles of cells stimulated by heat-inactivated E. coli compared to unstimulated cells (Figure 1A), comprising 933 up- (Additional file 1) and 545 downregulated (Additional file 2) genes. In contrast, stimulation of heat-inactivated $S$. aureus particles induced few gene expression changes as compared to control cells. Actually, only 16 genes exhibited altered expression at $24 \mathrm{~h}$ after $S$. aureus challenge (Figure 1B), of which 5 had not been annotated in the reference cow genome. Among the remaining DEGs, 4 were up-regulated and 7 down-regulated (Table S2). The Venn diagram in Figure 1C illustrates the large number of DEGs induced by E. coli. Of these, only $0.48 \%$ overlapped with $S$. aureus-induced expression changes, suggesting that E. coli-induced expression profiles were significantly different from those of $S$. aureus. The overlapping transcripts are shown in Figure 1D.

\subsection{Functional Analysis of Differentially Expressed Genes Induced by E. coli}

Hierarchical clustering of the transcripts that are significantly upregulated or downregulated by E. coli were generated (Figure 2A). Functional annotation analysis from Gene Ontology (GO) predictions revealed that the upregulated transcripts were significantly enriched in biological processes such as defense response to Gram-negative bacterium, positive regulation of Toll-like receptor signaling pathway, lipopolysaccharide-mediated signaling pathway, and positive regulation of NF-kB import into nucleus (Figure 2B). The downregulated genes were mainly associated with cell proliferation, cell death and metabolism process (Figure 2B). In Kyoto Encyclopedia of Genes and Genomes (KEGG) pathway analysis, the upregulated mRNAs were found to be mostly enriched in innate immune response pathways, including the tumor necrosis factor (TNF) signaling pathway, antigen processing and presentation, NF- $\mathrm{BB}$ signaling pathway, cytokine-cytokine receptor interaction, RIG-I-like receptor signaling pathway (RLR), Toll-like receptor (TLR) signaling pathway, and nucleotide-binding oligomerization domain (NOD)-like receptor signaling pathway (Figure 2C). The downregulated mRNAs were mostly enriched in the extracellular matrix-receptor (ECM-receptor) interaction pathway (15 DEGs) (Figure 2C).

GO enrichment and pathway analysis were not performed for DEGs induced by $S$. aureus particles due to the small number of genes. Functions of the DEGs are summarized in Table S2. 

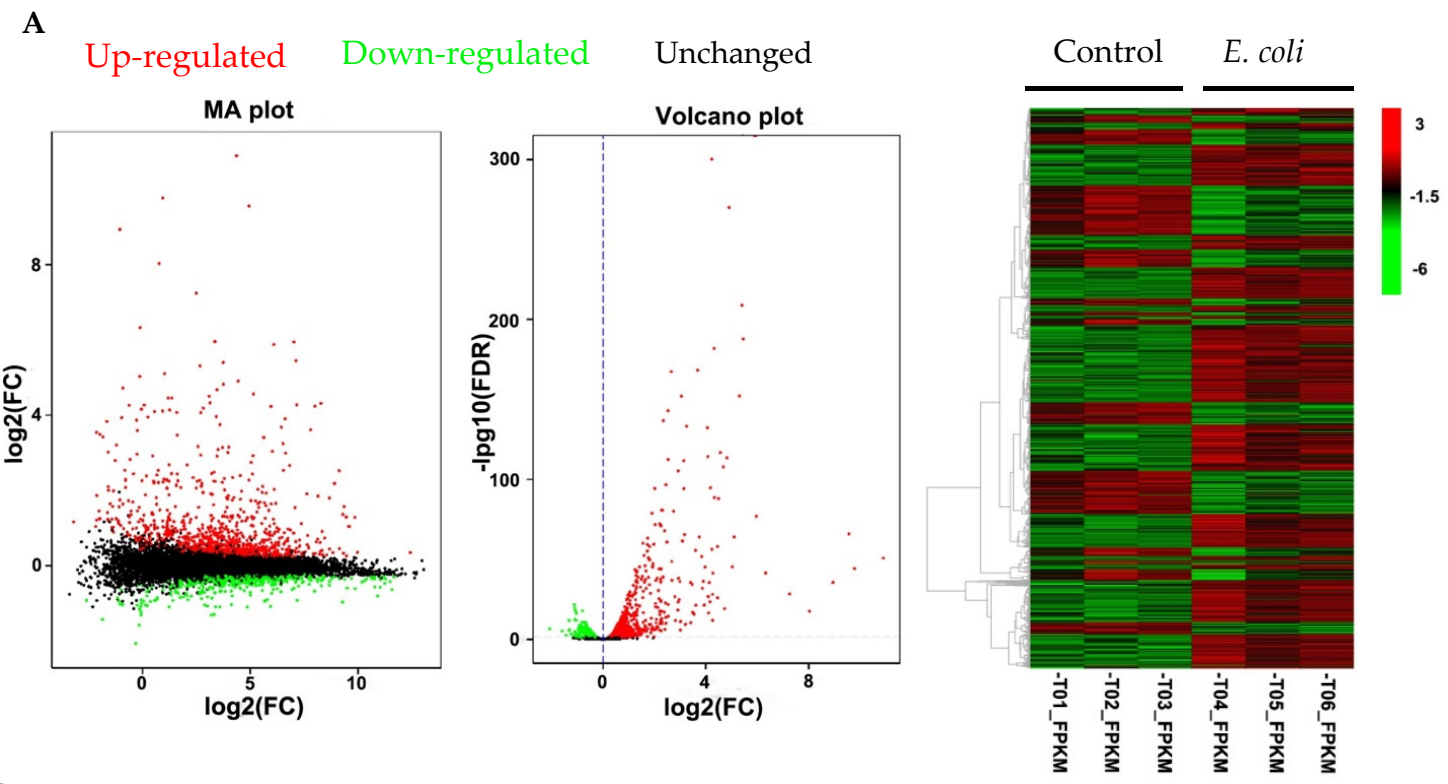

B
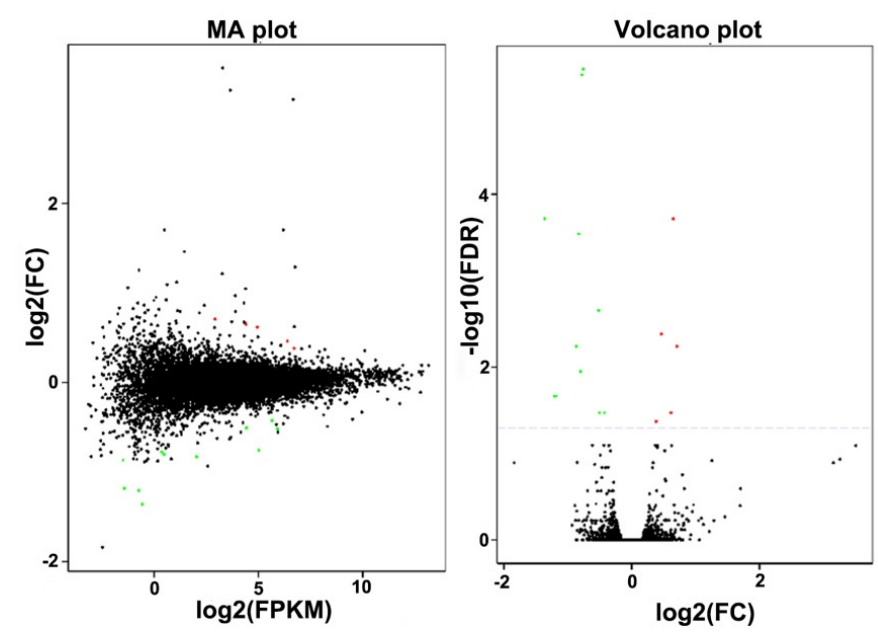

C

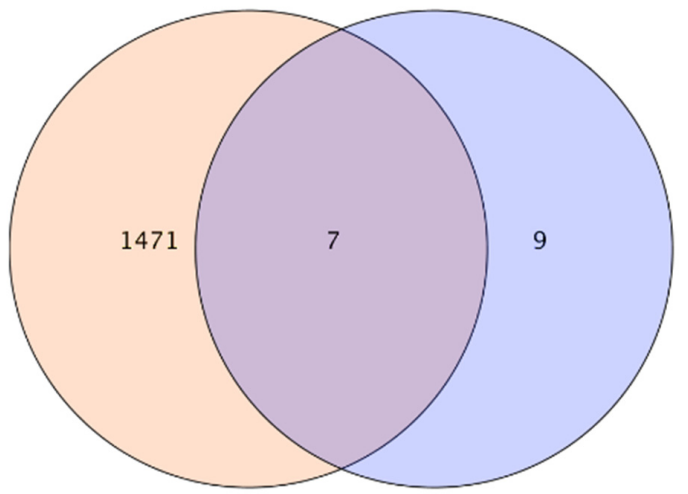

E. coli vs. control data set

S. aureus vs. control data set

D
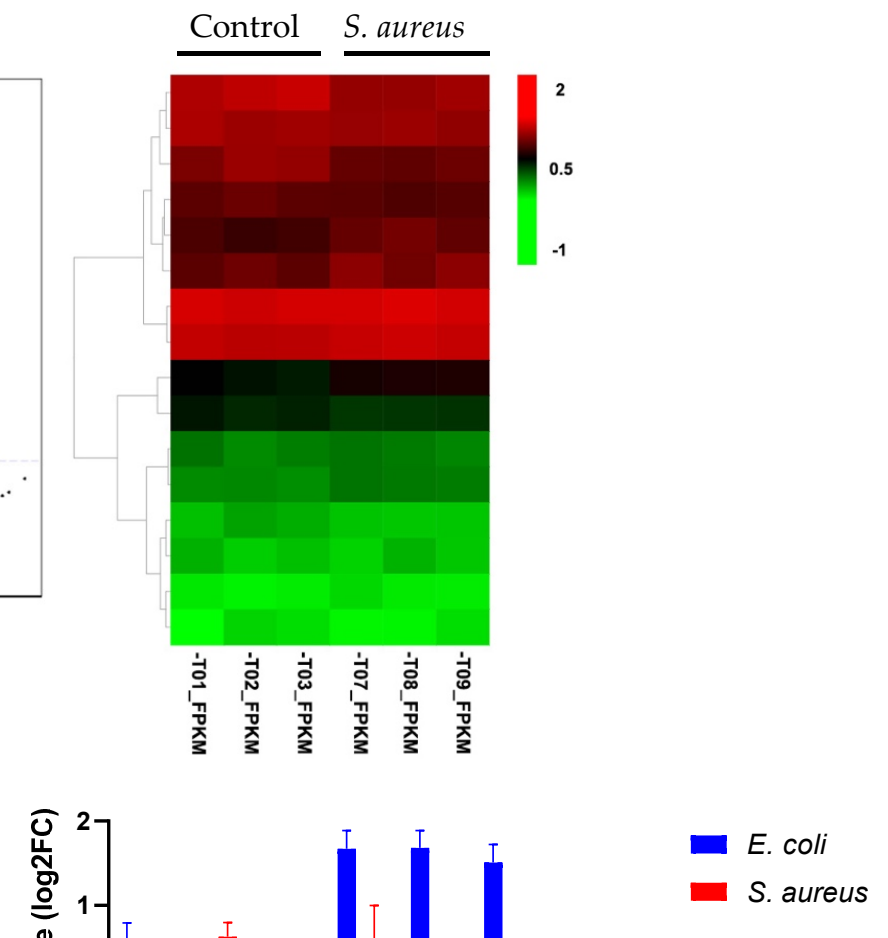

Figure 1. Gene expression profiling analysis of differential expression genes. (A,B) MA plots, volcano plots and hierarchical clustering showing differential expression profiles in primary cultures of bovine mammary epithelial cells (pbMECs) stimulated with heated-killed E. coli (A) or S. aureus (B) compared to unstimulated cells. Differentially expressed genes are established at $\log 2(\mathrm{FC})>0.1$ and false discovery rate $(\mathrm{FDR})<0.05$. FC, fold change; FPKM: Fragments Per Kilobase Million. 
(C) Venn diagram comparing the gene expression changes induced by heated-killed E. coli or S. aureus. (D) Expression patterns of the overlapping differentially expressed transcripts between E. coli- and S. aureus-stimulated cells compared with control showing in (C). Results are expressed as log2FC over unstimulated control cells. Data are mean \pm s.d. of triplicates.
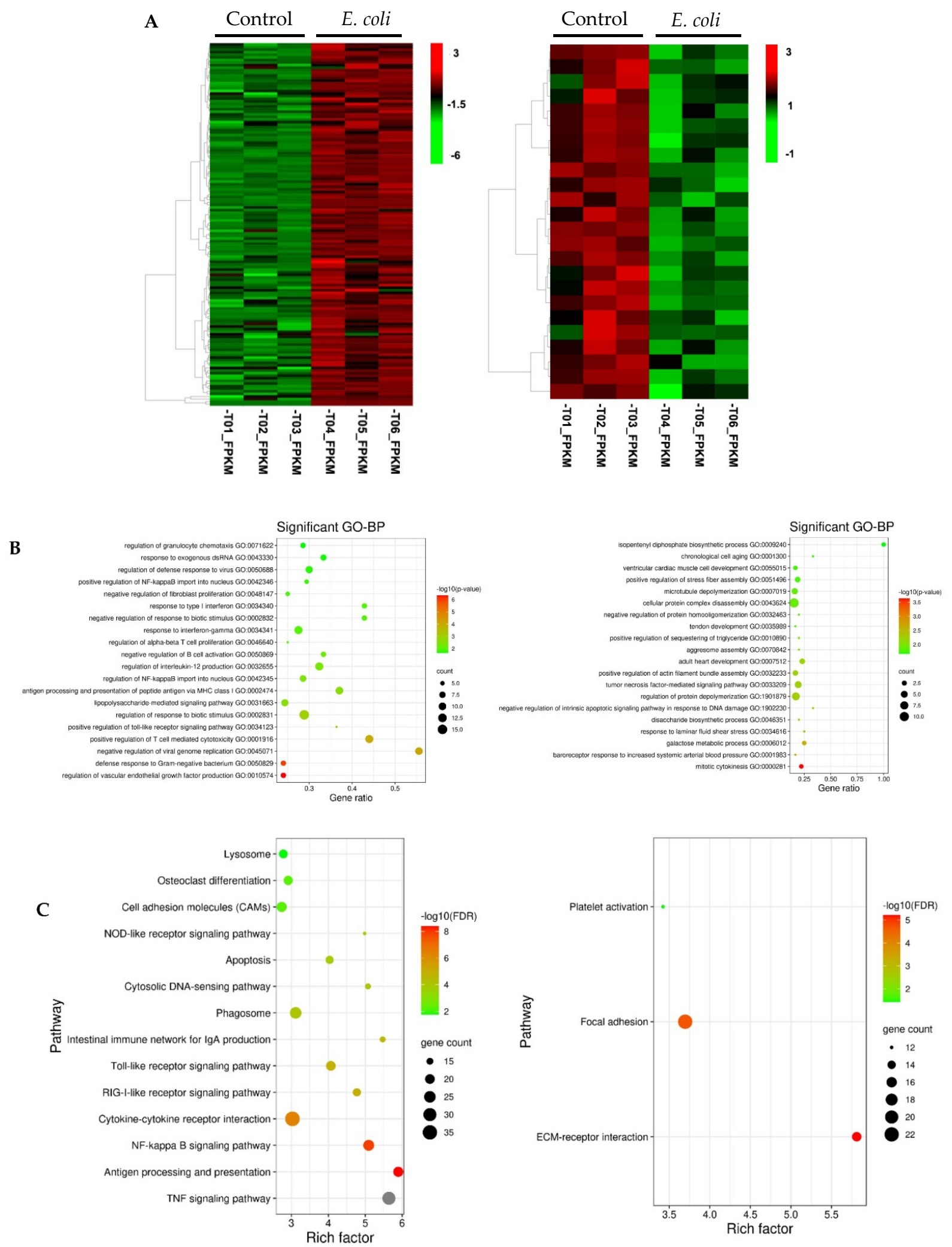

Figure 2. Function annotation and pathway analysis for the up- and downregulated genes between normal vs. E. coli samples. (A) Hierarchical clustering of gene expression for the up- (left panel) and downregulated (right panel) genes. Row 
represent individual genes and columns represent the expression changes of replicate for each investigated group. Red color indicates relative over-expression, while green color indicates relative under-expression. (B) Bubbleplot for GO enrichment of the upregulated (left panel) the downregulated genes (right panel) with statistically significant biological processes (FDR < 0.05). The top $20 \mathrm{GO}$ enrichment terms are presented. $y$-axis: ontological terms; $x$-axis, the gene ratio of enriched among the background genes in each ontological term. (C) Bubbleplot for KEGG pathway enrichment of the up- (left panel) and downregulated (right panel). Significant enrichment of a pathway was defined as FDR $<0.05$. y-axis, functional pathways; $x$-axis, rich factor. The size of the bubble is proportional to the number of genes assigned to the GO/KEGG entry and the color corresponds to the adjusted $p$ value. A high FDR is represented by red, and a low value is represented by green. GO, Gene Ontology; KEGG, Kyoto Encyclopedia of Genes and Genomes.

\subsection{Searching for Nrf2 Target Genes in DEGs from E. coli-Stimulated Cells}

Nrf2 pathway plays a vital role in maintaining cellular homeostasis and contributes to diverse cellular functions including inflammation [32]. We therefore asked whether the DEGs identified by RNA-seq analysis in the E. coli-treated samples versus normal contains previously reported Nrf2 regulated genes or not [14]. Since Nrf2 activation leads to upregulation of its downstream regulated genes, we focused on the upregulated DEGs for further analysis. Although the expression of the Nrf2 gene itself was not substantially changed, 16 genes downstream of Nrf2 were identified in the upregulated genes induced by E. coli (Table S3). Notably, all of these perturbations were absent in response to S. aureus stimulation (Figure 3A), suggesting that the ability of E. coli to potentiate an Nrf2 pathway response is not shared by $S$. aureus. To assess biological pathways overrepresented in these genes, we used online Reactome version (http:/ / reactome.org /, 7 February 2020) with the "pathways for human" option for functional enrichment analysis [33]. Gene network analysis suggested that the upregulated Nrf2 target genes were enriched in gene sets with a focus on metabolism and the immune system (Figure S1). As shown in Figure 3B, detoxification of reactive oxygen species, the NLRP3 inflammasome, and cell recruitment (proinflammatory response) were significantly enriched in the upregulated Nrf2 target genes.

\subsection{Validation of Selected Genes by qPCR}

To show the reliability of the DEG analysis of RNA-seq data, 4 genes showing differentially regulated expression in response to $E$. coli stimulation were quantified by using a SYBR-based real-time quantitative PCR (qPCR). More specifically, SOD2 and GRS1 were selected since, as mentioned above, they are transcriptionally regulated by Nrf2. Two additional genes, namely CCL5 and IL20RA, represent the highly upregulated and moderately downregulated genes, respectively. The NFE2L2 (Nrf2) gene, although not differentially regulated, was also selected for validation. Our results showed that the qPCR expression patterns of these genes agreed with the RNA-seq results in terms of direction and magnitude, with the exception that the relative expression of Nrf2 detected by qPCR, which was higher than by RNA-seq, but with a similar trend between the two methods (Figure 4). These results indicate a close correlation between qPCR and RNA-seq data. 

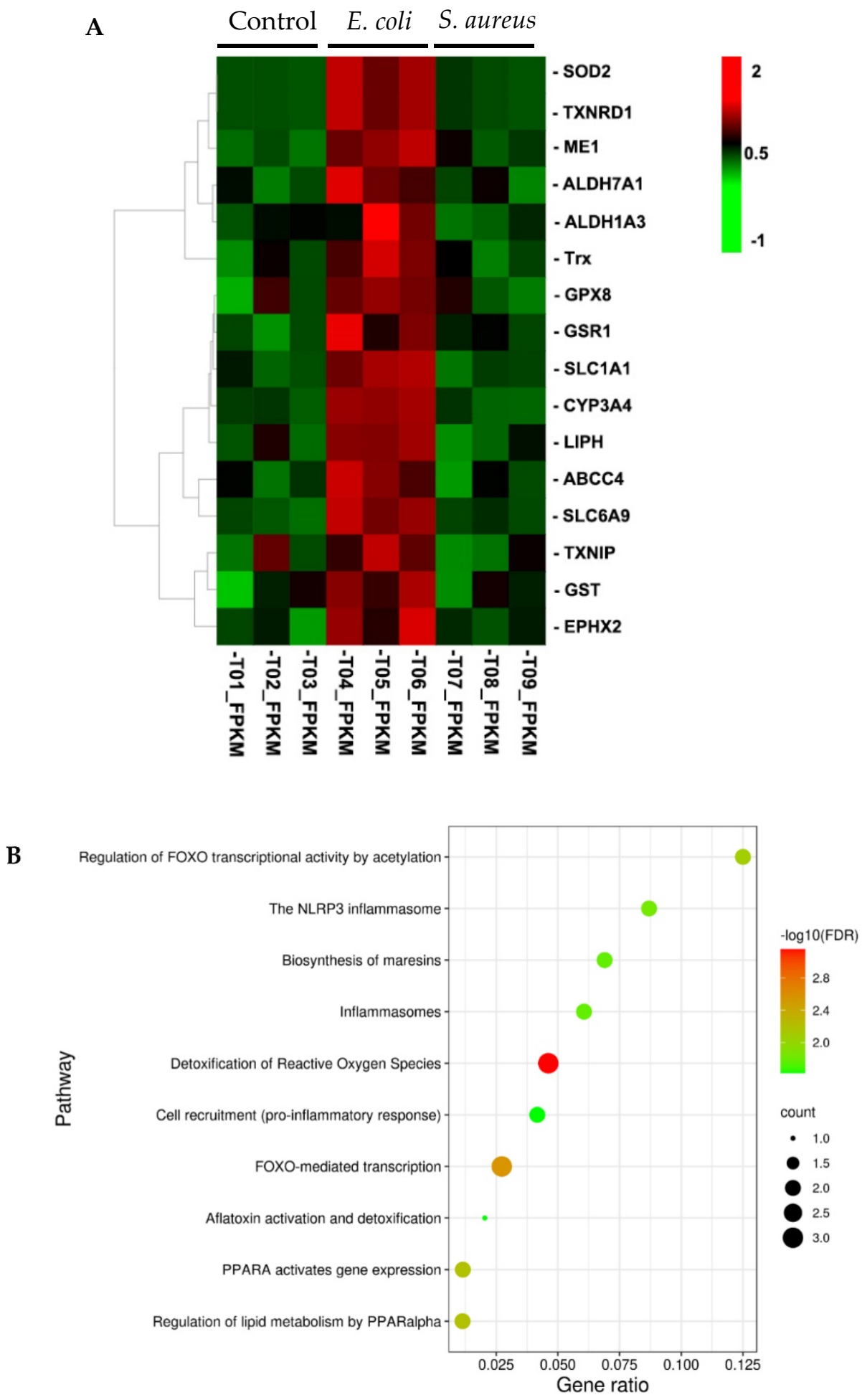

Figure 3. Reactome pathway analysis. (A) Hierarchical clustering of gene expression for the 16 selected Nrf2 target genes. Rows represent individual genes and columns represent the expression changes of replicate for each investigated group. Red color indicates relative over-expression, while green color indicates relative under-expression. (B) Bubble plots displaying over-represented Reactome pathways. $y$-axis, functional pathways; $x$-axis, the gene ratio of enriched relative to all genes in each pathway. The size of the bubble is proportional to the number of genes assigned to pathway and the color corresponds to the adjusted $p$ value. A high FDR is represented by red, and a low value is represented by green. 


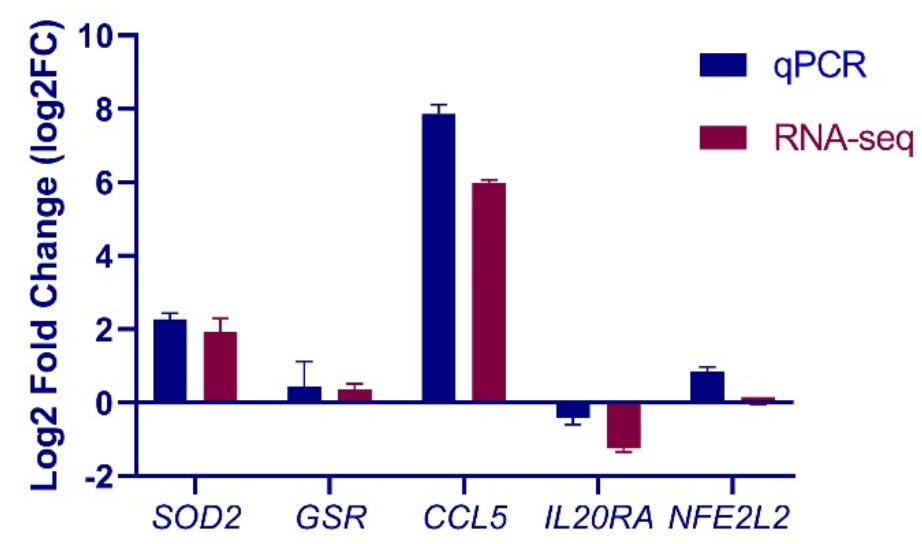

Figure 4. Real-time quantitative PCR (qPCR) validation of RNA sequencing (RNA-Seq) data. Relative mRNA abundance of Nrf2, Chemokine (C-C motif) ligand 5 (CCL5), glutathione reductase (GSR1), superoxide dismutase 2 (SOD2) and interleukin 20 receptor alpha (IL20RA) in E. coli-stimulated cells determined by RNA-seq and qPCR measurements. Results are expressed as log2FC over unstimulated control cells. Data are mean \pm s.d. of triplicates.

\subsection{Different Response of Nrf2 Pathway to E. coli and S. aureus}

To gain further insights into the earlier response of the Nrf2 pathway to $E$. coli and $S$. aureus, we treated the cells with E. coli and S. aureus particles for $6-12 \mathrm{~h}$ and detected by qPCR the expression of Nqo-1 and Gclm, two notable targets of Nrf2 activation. In accordance with previous findings [34], E. coli stimulation resulted in an increased expression in both Nqo-1 and Gclm (Figure 5A), suggesting Nrf2 activation. In contrast, no significant alteration in Nqo-1 and Gclm was observed in S. aureus-treated cells by $12 \mathrm{~h}$ (Figure 5B). Considering that Nrf2 transactivates cytoprotective genes are only in the nucleus [32], we next determined by immunoblot analysis the Nrf2 protein levels in the cytoplasmic and nuclear extracts. Cells stimulated by E. coli O111:B4-derived crude lipopolysaccharide (LPS) was also analyzed to verify the results from E. coli. Although the predicted molecular weight of Nrf2 is $\sim 55-65$ kilodalton $(\mathrm{kDa})$, it is believed that the biologically relevant band migrates between $\sim 95$ and $110 \mathrm{kDa}$ on SDS-PAGE gel [35]. Indeed, two major bands between the 60 and $140 \mathrm{kDa}$ molecular weight markers were present in our immunoblots (Figure S2) and only the $\sim 110 \mathrm{kDa}$ bands were selected for further analyses. In support of a previous report [36], Nrf2 was almost undetectable in the cytoplasmic fractions, regardless of the treatments (Figure 5C). Immunoblot analysis showed that E. coli particles induced an increase in Nrf2 accumulation in the nucleus, an effect that was reproducible in LPS-treated cells (Figure 5C). The data suggest that LPS-positive bacterium activates Nrf2 nuclear translocation, thereby initiating downstream transcription activities. In contrast, nuclear Nrf2 levels were slightly downregulated by S. aureus (Figure 5C). To confirm these results, we performed immunofluorescent staining of Nrf2, which demonstrated strongly increased Nrf2 signals in the nuclei of cells stimulated by LPS and E. coli particles as compared to normal cells; however, the nuclear immunofluorescence signals were weakened in response to $S$. aureus exposure (Figure 5D). Taken together, the results suggest that E. coli and $S$. aureus differentially regulate Nrf2 nuclear translocation in pbMECs.

\subsection{Nrf2 Positively Regulates the Inflammatory Response in pbMECs}

Multiple studies have suggested that Nrf2 confers protection against inflammation [37]. However, Nrf2 knockout in murine fibroblasts has been shown to suppress p50 and p65 subunits of NF- $\mathrm{kB}$ [38], a master regulator of innate immune responses. We next used an LPS-stimulated inflammatory cell model to verify the contribution of Nrf2 in the inflammatory response of pbMECs. Nrf2 siRNA was employed to downregulate the gene and protein expressions (Figure 6A). No significant effect of Nrf2 knockdown on cell viability was determined before or after LPS stimulation (Figure 6B). As shown in Figure 6C, siRNA-mediated Nrf2 knockdown attenuated LPS-induced phosphorylation 
of both IкB $\alpha$ and NF- $\mathrm{kB}$ p65 as compared to negative control siRNA (NC-siRNA). We also measured mRNA levels by qPCR of genes encoding proinflammatory cytokines interleukin (IL)-1 $\beta$, IL-6 and IL-8. Corresponding to the immunoblotting data, LPS-induced transcriptional upregulation of the cytokines was suppressed by Nrf2 siRNA (Figure 6D). The data suggest that Nrf2 positively regulates the innate immune response of bovine mammary epithelial cells.

A

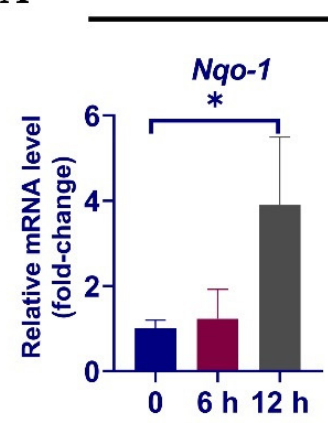

E. coli

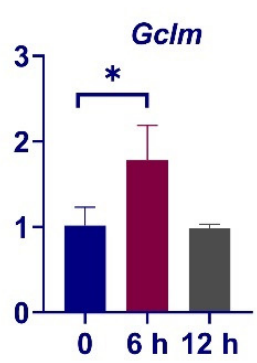

B

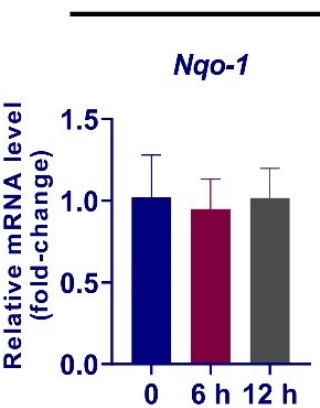

S. aureus

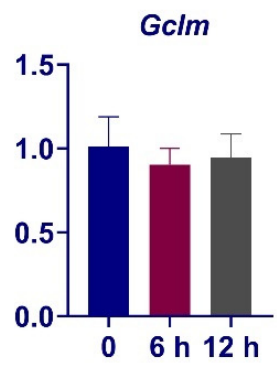

C

E. coli

LPS

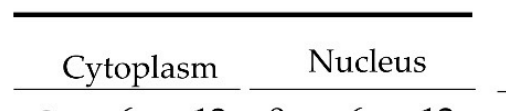

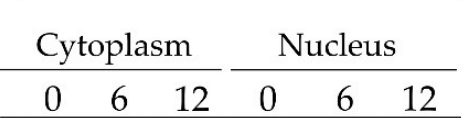

Nrf2

GADPH

Cytoplasm $\quad$ Nucleus
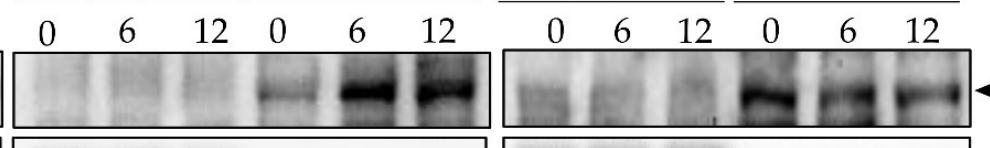

$110 \mathrm{kDa}$
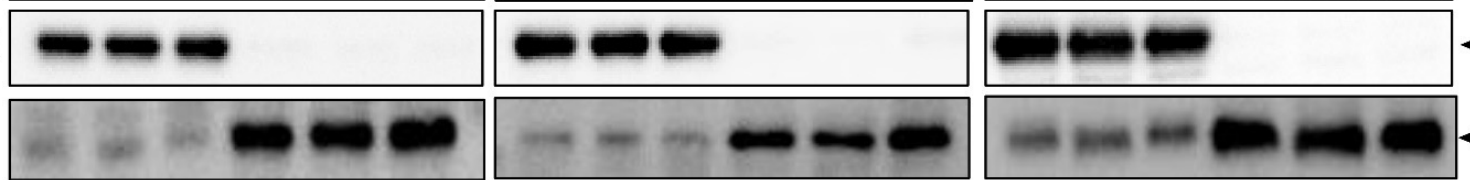

$35 \mathrm{kDa}$

Histone

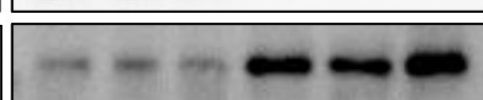

$15 \mathrm{kDa}$

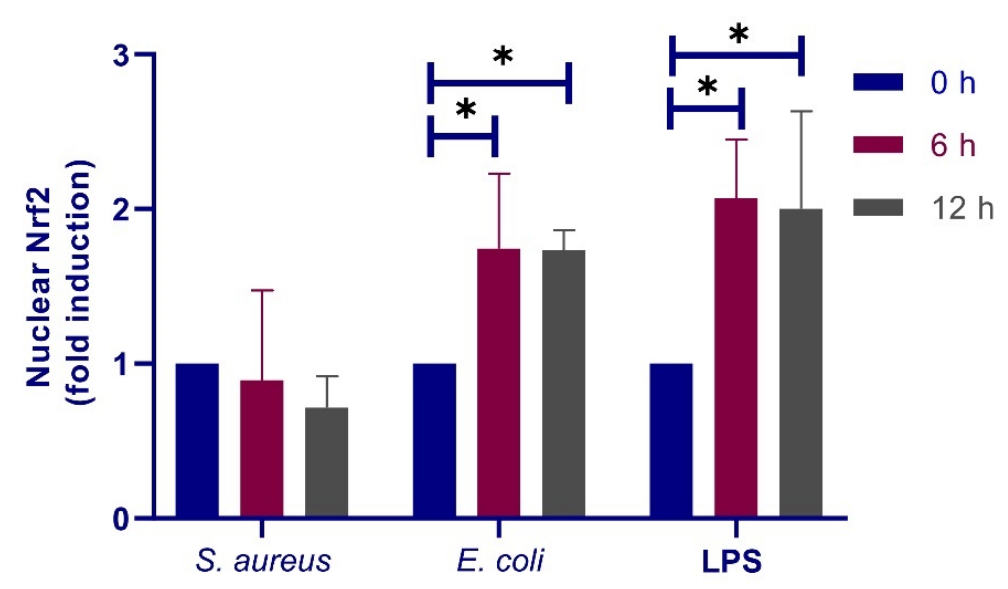

Figure 5. Cont. 

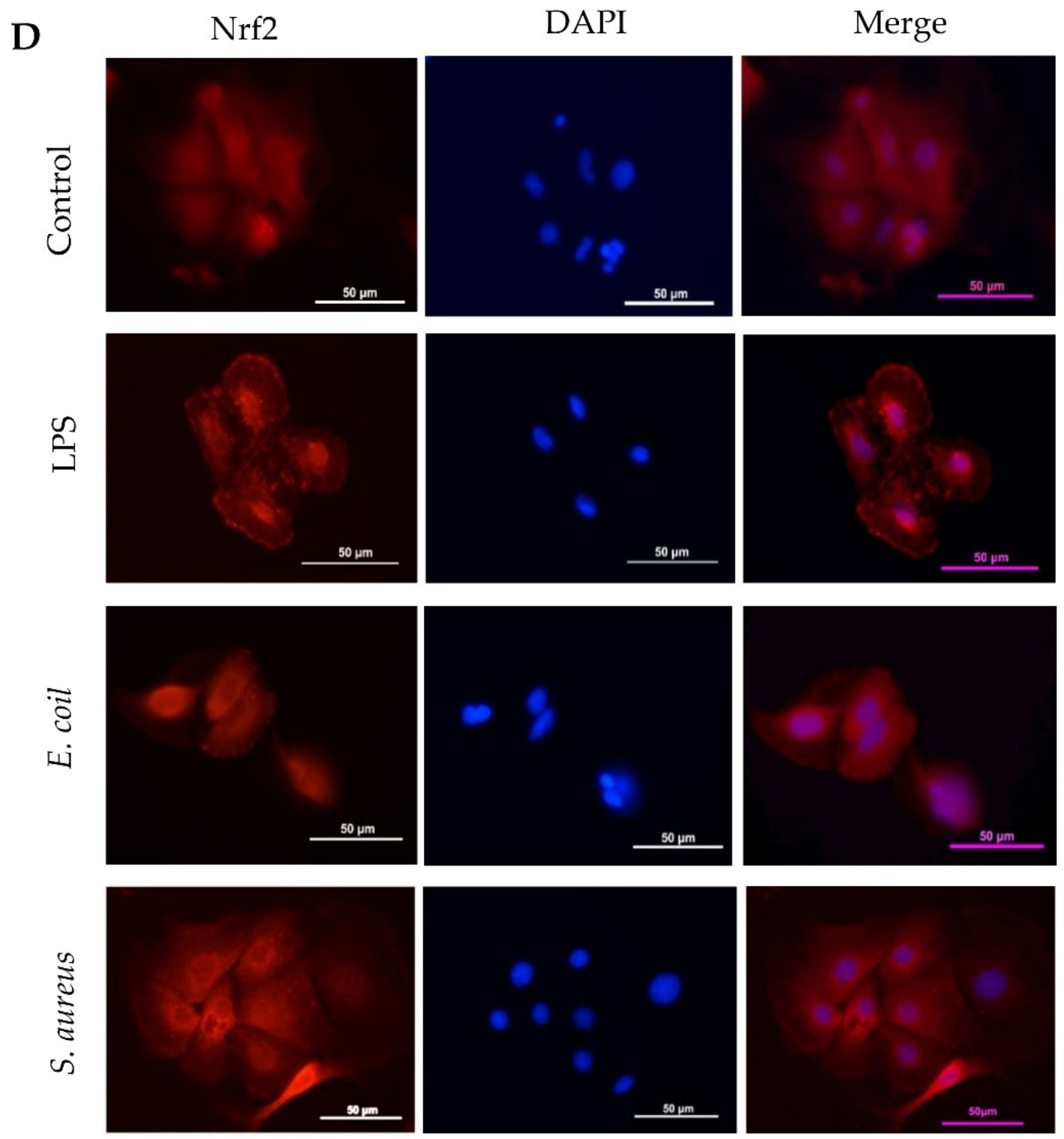

Figure 5. Response of Nrf2 pathway to E. coli and S. aureus. (A,B) pbMECs were treated with heat-killed E. coli $\left(1 \times 10^{7}\right.$ particles $\left./ \mathrm{mL}\right)(\mathbf{A})$ and $S$. aureus $\left(1 \times 10^{7}\right.$ particles $\left./ \mathrm{mL}\right)(\mathbf{B})$, respectively, for the indicated time. Nqo- 1 and Gclm mRNA expression was quantified by qPCR. Fold change is relative to control cells. Data are means \pm s.d. of three triplicates and are representative of 3 separate experiments. (C) Cytoplasmic and nuclear proteins extracted from cells treated with E. coli $\left(1 \times 10^{7}\right.$ particles $\left./ \mathrm{mL}\right)$, S. aureus $\left(1 \times 10^{7}\right.$ particles $\left./ \mathrm{mL}\right)$ and lipopolysaccharides $(\mathrm{LPS})(10 \mu \mathrm{g} / \mathrm{mL}) \mathrm{were}$ analyzed by immunoblotting with anti-Nrf2. GADPH and Histone are shown as loading controls, respectively. Nuclear Nrf2 protein levels were determined with densitometry analyses after normalization to Histone. Bars are means \pm s.d. of three triplicates and are representative of 3 separate experiments. ${ }^{*} p<0.05$. (D) After treatment with E. coli, LPS or S. aureus for $12 \mathrm{~h}$ as described above, cells were subjected to immunofluorescent staining. Nrf2 was stained with an Alexa Fluor 594-conjugated secondary antibody. Cell nuclei were visualized by $4^{\prime}, 6$-Diamidino-2-phenylindole dihydrochloride (DAPI). The images were obtained using inverted fluorescence microscopy. 
A

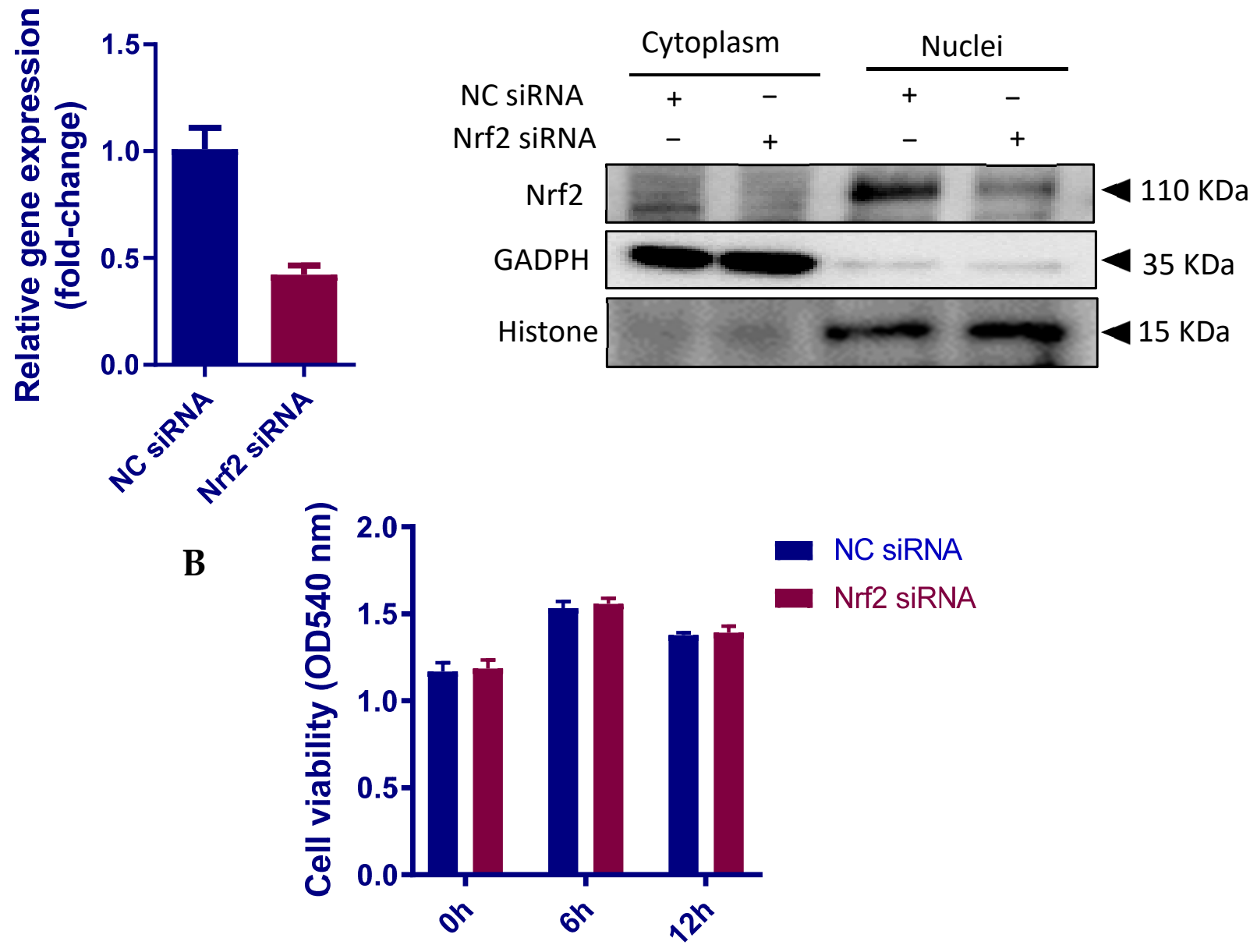

Figure 6. Cont. 

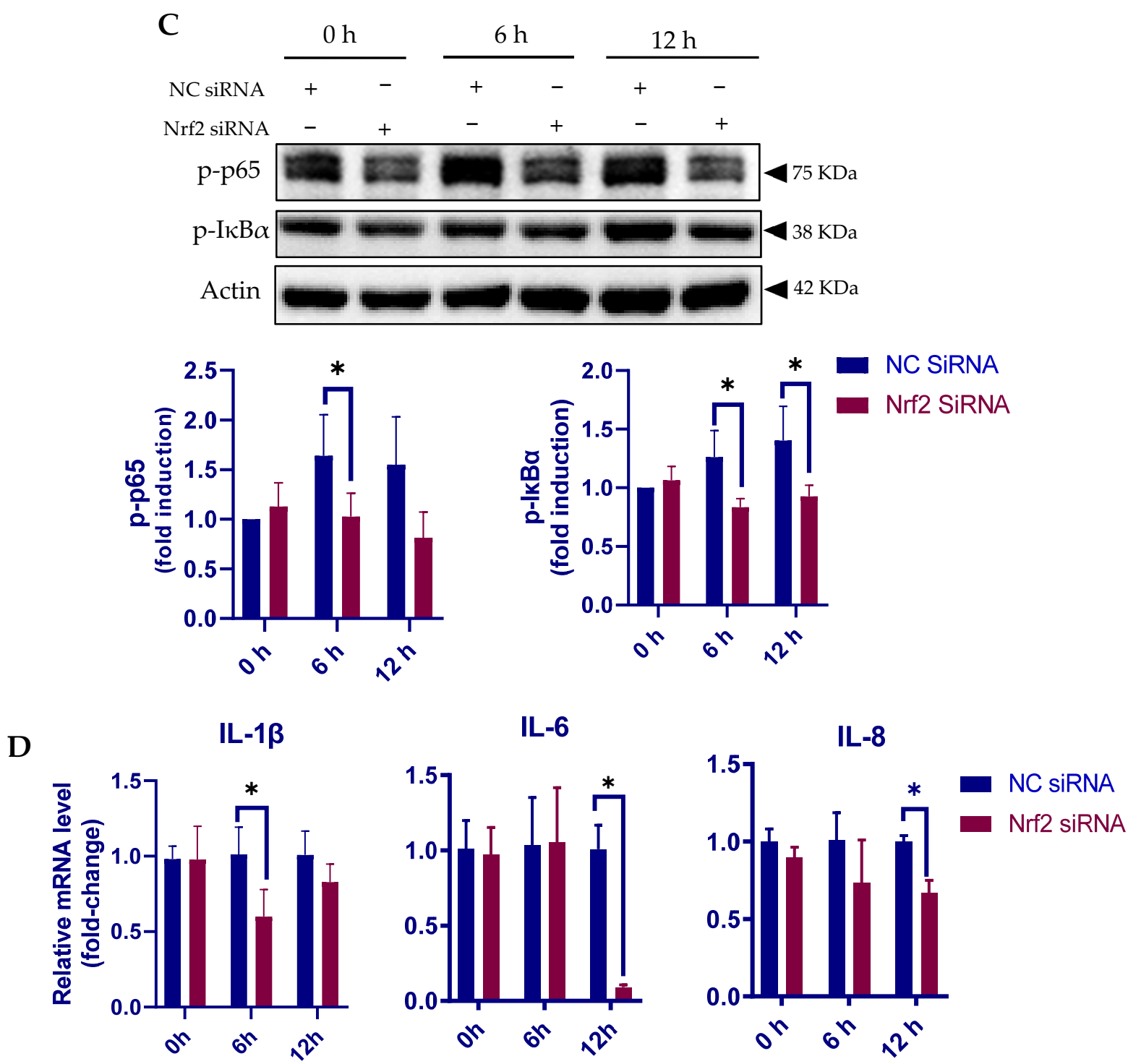

Figure 6. Nrf2 knockout attenuates LPS-induced inflammatory response in pbMECs. Cells were transfected with siRNA targeting Nrf2 or a negative control (NC) siRNA for $48 \mathrm{~h}$, and the efficiency of Nrf2 knockdown was confirmed by RT-qPCR (left panel) and Western blotting (right panel). $\beta$-actin was used for the equal loading control (A). The cells were then incubated with LPS $(10 \mu \mathrm{g} / \mathrm{mL})$ for the indicated time. Cell viability was determined by MTT assay. The results are the mean \pm s.d. of six replicates (B). The cells were then lysed with RIPA lysis buffer and subjected to immunoblot analysis against

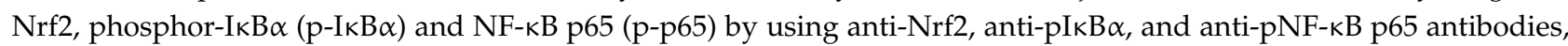
respectively. $\beta$-actin was used for the equal loading control. p-p65 and p- $\mathrm{I} \kappa \mathrm{B} \alpha$ levels were quantified with densitometry analyses after normalization to Actin. Bars are means \pm s.d. of three triplicates and are representative of 3 separate experiments (C). Total RNAs were prepared and subjected to qPCR analyses for the mRNA levels of IL-1 $\beta, T N F-\alpha, I L-6$ and $I L-8$. The results are the mean \pm s.d. of three replicates and are representative of 3 separate experiments $(\mathbf{D}) .{ }^{*} p<0.05$.

Based on these findings, we postulated that Nrf2 overexpression might enhance the cytokine responses of mammary epithelial cells to $S$. aureus. In order to overexpress Nrf2, we first transfected pbMECs with a pEGFP-C3-Nrf2 plasmid, but we failed to determine neither GFP fluorescence nor GFP protein in the transfected cells, although the relative Nrf2 mRNA abundance was increased more than 1000-fold of the control cells (data not shown). It is thus our belief that exogenous Nrf2 protein was rapidly degraded in the cytoplasm after translation. In order to reduce exogenous Nrf2 degradation, we next transfected the cells with a GFP-expressing Nrf2 plasmid containing tripartite nuclear localization signal (NLS-Nrf2) to ensure the nuclear import. Fluorescence of GFP was detectable in 
nuclei $24 \mathrm{~h}$ after transfection and increased accumulation of GFP-Nrf2 was confirmed by Western blot analysis (Figure 7A). However, only limited number of cells ( 20\%) displayed GFP fluorescence. Nevertheless, treatment of Nrf2 plasmid increased NF- $\mathrm{B}$ activity following $S$. aureus stimulation as compared to the mock plasmid (Figure 7B). Interestingly and unexplainably, although Nrf2 plasmid downregulated IL-6 expression under normal conditions, which is in agreement with a previous report using macrophage [37], a moderate increase in IL-6 mRNA was determined in cells bearing Nrf2 plasmid as compared to mock plasmid following $S$. aureus stimulation (Figure 7C). In contrast to $I L-6$, and in line with a previous report [39], Nrf2 plasmid induced IL-8 gene expression in unstimulated cells, and this effect was further augmented in the presence of $S$. aureus (Figure 7D). Similarly, the expression of $I L-6$ and $I L-8$ in response to $S$. aureus was augmented by tBHQ (Figure S5). Taken together, contrary to the widely accepted view that Nrf2 has an anti-inflammatory effect [37], our findings suggest that Nrf2 induction is required for pbMECs to mount an efficient inflammatory response.

A

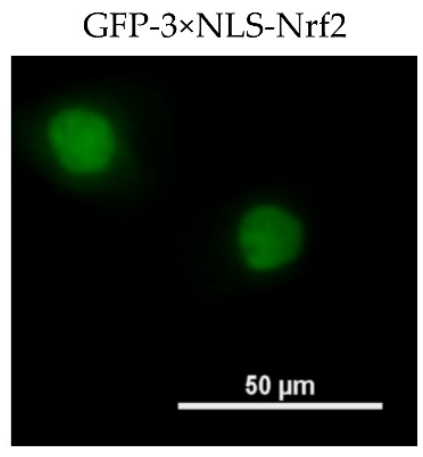

DAPI

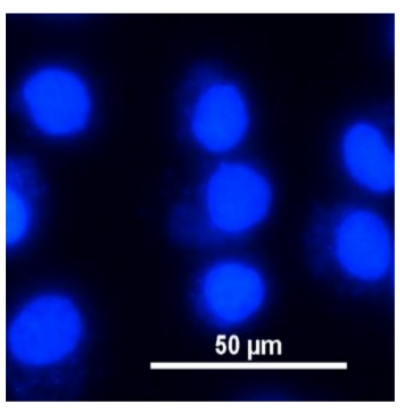

Merged
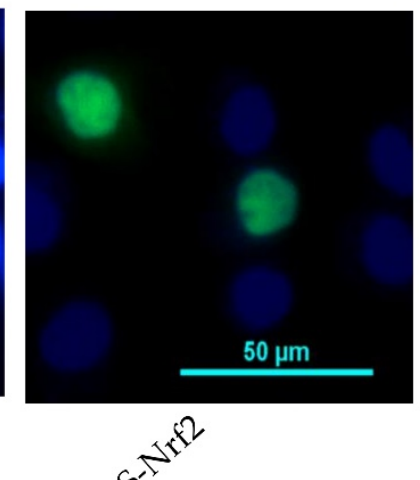

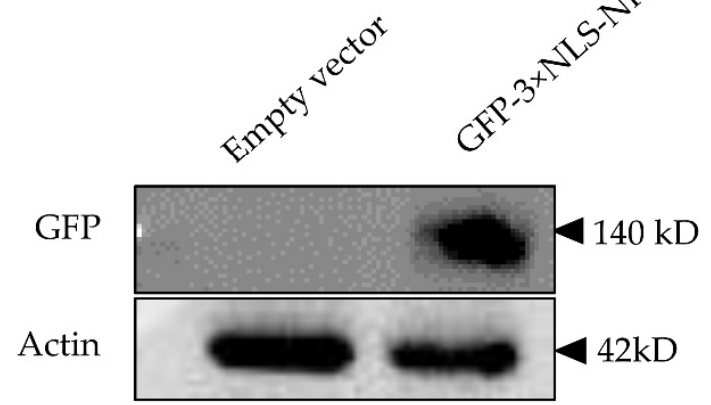

B

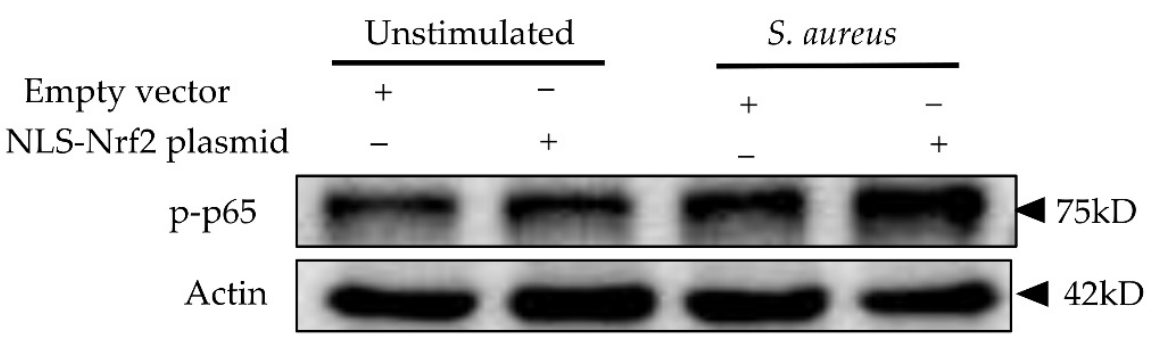

Figure 7. Cont. 

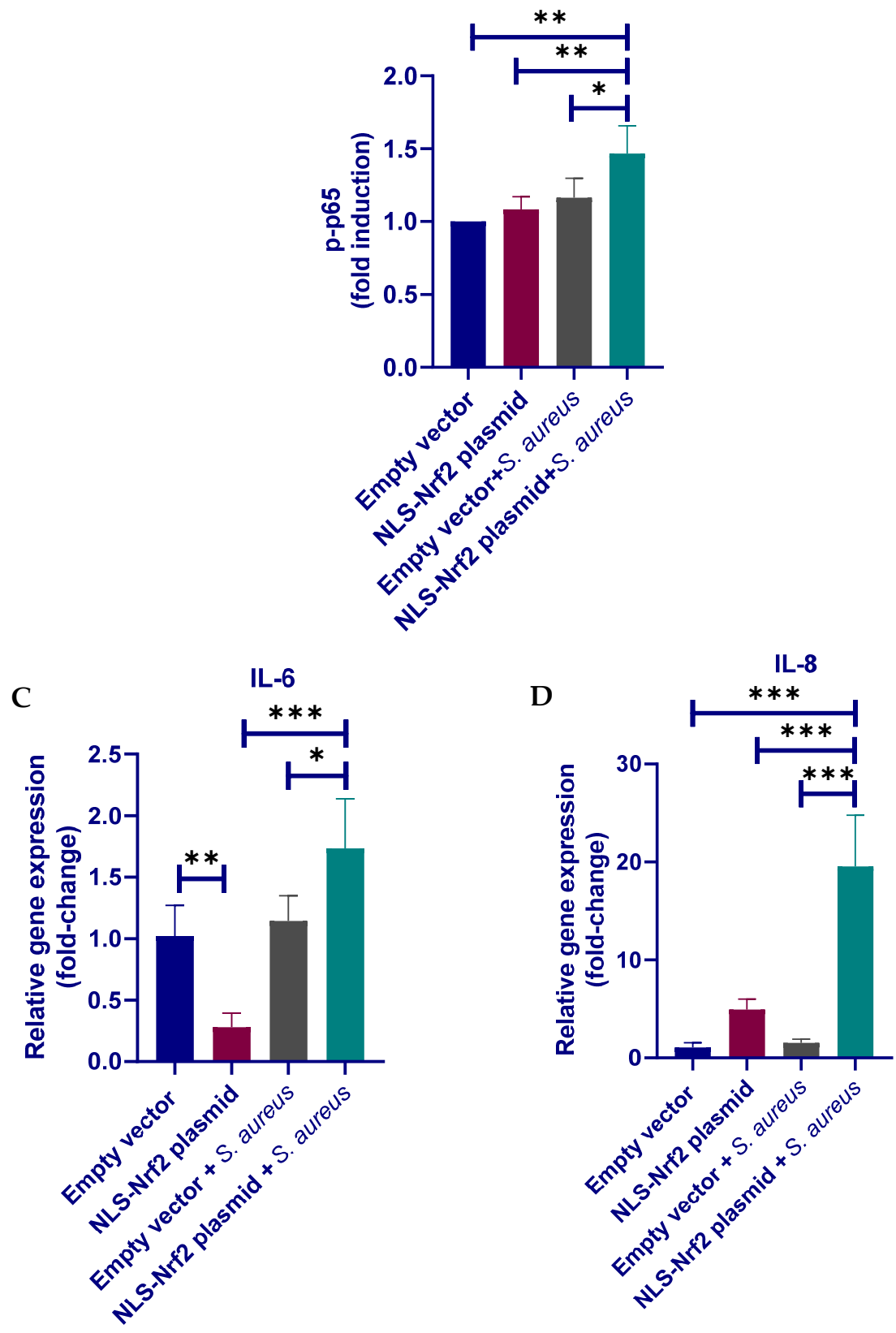

Figure 7. Evaluation of Nrf2 overexpression on the inflammatory responses of pbMECs to S. aureus. (A) Confirmation of Nrf2 overexpression. Cells were transfected with a GFP-expressing Nrf2 plasmid containing tripartite nuclear localization signal (NLS-Nrf2) for $24 \mathrm{~h}$. GFP fluorescence was determined under a microscope and whole-cell extracts were analyzed by immunoblotting with anti-GFP. (B) Evaluation of the effect of Nrf2 overexpression on NF-kB p65 activation in response to $S$. aureus. The cells transfected with GFP-expressing Nrf2 plasmid were incubated with S. aureus for $6 \mathrm{~h}$. Whole-cell extracts were analyzed by immunoblotting with anti-phospho NF-kB p65 antibody (p-p65). $\beta$-actin was used for the equal loading control. p-p65 levels were determined with densitometry analyses after normalization to Actin. Bars are means \pm s.d. of three triplicates and are representative of 3 separate experiments. (C,D) Evaluation of the effect of Nrf2 overexpression on the expression of pro-inflammatory cytokines was induced by S. aureus. The cells transfected with GFP-expressing Nrf2 plasmid were incubated with $S$. aureus for $6 \mathrm{~h}$. Total RNAs were prepared and subjected to qPCR analyses for the mRNA levels of $I L-6$ and $I L-8$. The results are the mean \pm s.d. of three replicates and are representative of 3 separate experiments (D). ${ }^{*} p<0.05,{ }^{* *} p<0.01$ and ${ }^{* *} p<0.001$. 


\subsection{S. aureus-Induced Nrf2 Activation Impairment Is Not Due to Inadequate ROS Production}

Under normal conditions, Nrf2 forms a complex with Keap1 (kelch-like ECH-associated protein 1), which functions as a key repressor of Nrf2, in cytoplasm in the absence of an activator. Keap1-Nrf2 pathway is activated when cells are exposed to oxidative and electrophilic stresses of both exogenous and endogenous origins [12]. To demonstrate that impairment of Nrf2 activation in response to S. aureus is not due to inadequate ROS production, intracellular ROS level was measured by using a $2^{\prime}, 7^{\prime}$-dichlorofluorescin diacetate (DCFH-DA) probe. In line with an earlier study, pbMEC exposure to $S$. aureus particles triggered a time-dependent increase in ROS, which was comparable to that in LPS-treated cells (positive control) by $12 \mathrm{~h}$ (Figure 8). To rule out the possibility that the Nrf2 pathway in pbMECs is not sensitive to oxidative stress, we used the LPS-stimulated cell model to determine the effect of N-acetylcysteine (NAC), an ROS scavenger, on Nrf2 activation. qPCR analysis showed that treatment with $10 \mathrm{mM}$ NAC led to a significant downregulation in the expression of Nrf2 target genes, such as Nqo-1, Gclm, Sod1 and $p 62$, as compared to mock-treatment (Figure S2). Considering that cells treated with $S$. aureus also demonstrated increased ROS production but had impaired Nrf2 activation, we wondered if $S$. aureus could induce Nrf2 degradation. To this end, we pretreated the cells with tert-butylhydroquinone (tBHQ), a powerful $\mathrm{Nrf2}$ inducer [40,41], for $2 \mathrm{~h}$ to induce robust Nrf2 activation prior to $S$. aureus exposure (Figure S3). If $S$. aureus induces Nrf2 degradation, one can expect a decline in the transactivation activity of Nrf2. Indeed, we found that the induction of Nrf2 target genes by tBHQ was not affected by $S$. aureus particles (Figure S4), suggesting that $S$. aureus-induced impairment of Nrf2 activation is not due to increased Nrf2 degradation.

\subsection{Both S. aureus and E. coli Upregulates p62/SQSTM1 Levels but Differentially Modify p62/SQSTM1 Phosphorylation}

We next questioned whether E. coli and S. aureus differentially modulates Keap1 degradation in pbMECs. Immunoblot analysis showed that both E. coli and LPS triggered a significant reduction in cytoplasmic Keap1. By contrast, the levels of cytoplasmic Keap1 was not changed in response to S. aureus (Figure 9). A small amount of Keap1 was also determined in the nuclear fractions (Figure 9A), possibly due to the cytoplasmic contamination. Therefore, this portion was not taken into consideration. Taken together, the results suggest that Keap1 degradation is involved in E. coli-induced Nrf2 activation in pbMECs, and that a lack of such a mechanism may account for the impairment of Nrf2 activation during S. aureus infection.

To further clarify the mechanisms by which $E$. coli and S. aureus differentially regulate Keap1 degradation, we focused on p62/sequestosome 1 (SQSTM1), a stress sensor that has been shown to disrupt the Nrf2-Keap1 complex by competing with Keap1 for Nrf2 binding and to target Keap1 for autophagic degradation [27]. This mechanism of activating Nrf2 is non-canonical, in contrast to the previously described canonical pathway by which Nrf2 is activated via oxidative modifications in the cysteine residues in Keap1 [42,43]. LPS-induced Nrf2 activation has been previously attributed to p62/SQSTM1-mediated Keap1 degradation [44]. Consistent with this study, p62/SQSTM1 levels were significantly upregulated by E. coli as well as LPS. Similarly, the levels of p62/SQSTM1 protein were also upregulated following S. aureus treatment (Figure 10A). The results led us to question whether increased amount of p62/SQSTM1 plays a role in Keap1 turnover in our cell models. Therefore, we treated the cells with an expressing plasmid encoding p62/SQSTM1. Overexpression of p62/SQSTM1 was confirmed by Western blot analysis (Figure 10B). As expected, p62/SQSTM1 overexpression enhanced Keap1 turnover in the presence of E. coli; however, this effect was not evident when cells were exposed to S. aureus (Figure 10B). In support of this result, the transcription of Nrf2 target genes in p62/SQSTM1-overexpressing cells was not activated by S. aureus (Figure 10C). The data suggest that $S$. aureus dampens p62/SQSTM1-mediated Keap1 turnover. To this point, we were interested to see the level of phosphorylation of p62/SQSTM1 at Ser349 (Ser351 in mouse), which rises affinity 
of p62/SQSTM1 for Keap1 and contributes subsequent Nrf2 activation [27,45]. Western blot analysis showed that Ser349-phosphorylated p62/SQSTM1 (pS349-p62) levels were markedly increased in response to E. coli stimulation; by contrast, $S$. aureus particles induced a significant reduction in pS349-p62 level in a time-dependent manner (Figure 10D). Taken together, the results strongly suggest that $S$. aureus perturbs p62/SQSTM1-mediated Keap1 degradation through perturbing phosphorylation of p62/SQSTM1.

A

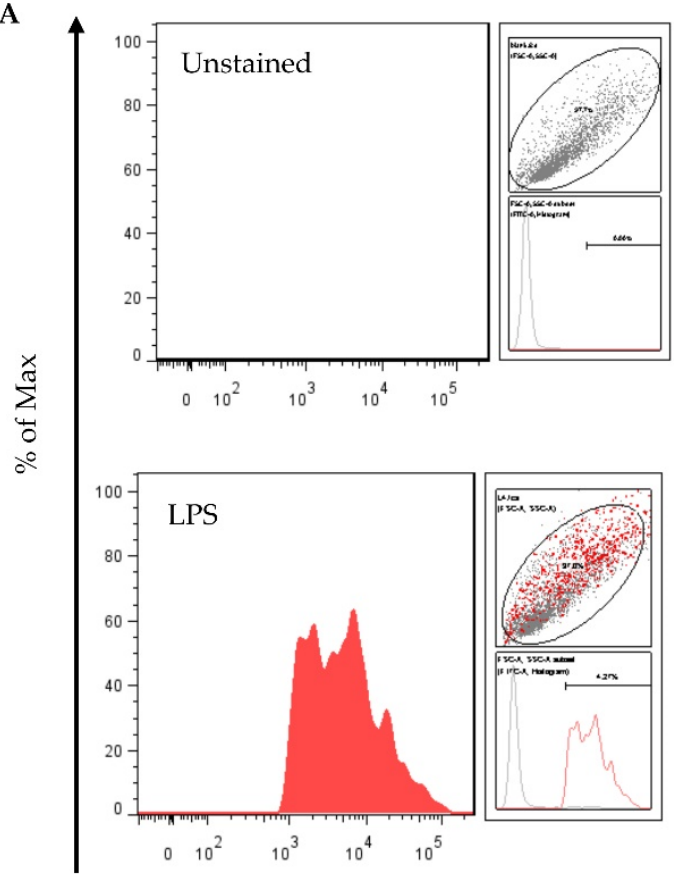

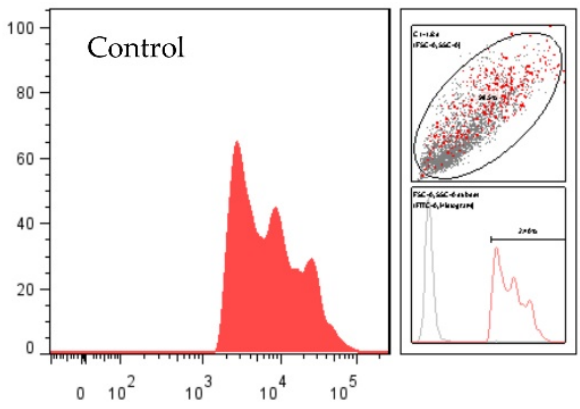

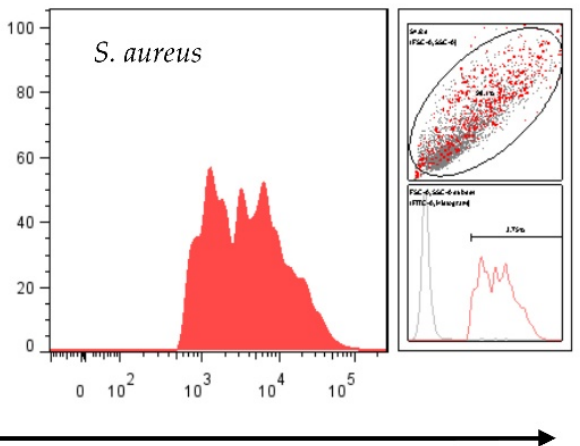

DCF-DA FITC-A
B

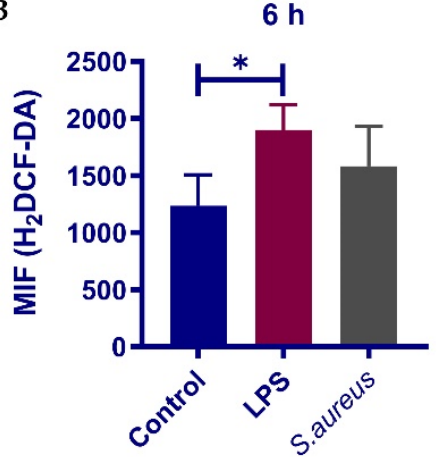

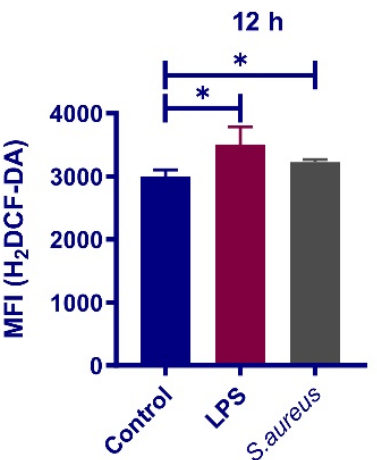

Figure 8. Determination of the production of ROS using the $2^{\prime}, 7^{\prime}$-dichlorofluorescin diacetate (DCF-DA) probe. pbMECs were treated with LPS $(10 \mu \mathrm{g} / \mathrm{mL})$ or S. aureus $\left(1 \times 10^{7}\right.$ particles $\left./ \mathrm{mL}\right)$ for 6 and $12 \mathrm{~h}$, followed by incubation with serum-free medium containing H2DCF-DA $(20 \mu \mathrm{M})$ for $30 \mathrm{~min}$. 2,7-dichlorofluorescein (DCF) fluorescence was measured using flow cytometry. (A) Representative flow cytometry histograms showing DCF-DA staining of cells treated with LPS or S. aureus for $12 \mathrm{~h}$. (B) Mean fluorescence intensities (MIF) are shown as bar graph. Data are mean \pm s.d. $(n=3) .{ }^{*} p<0.05$. 


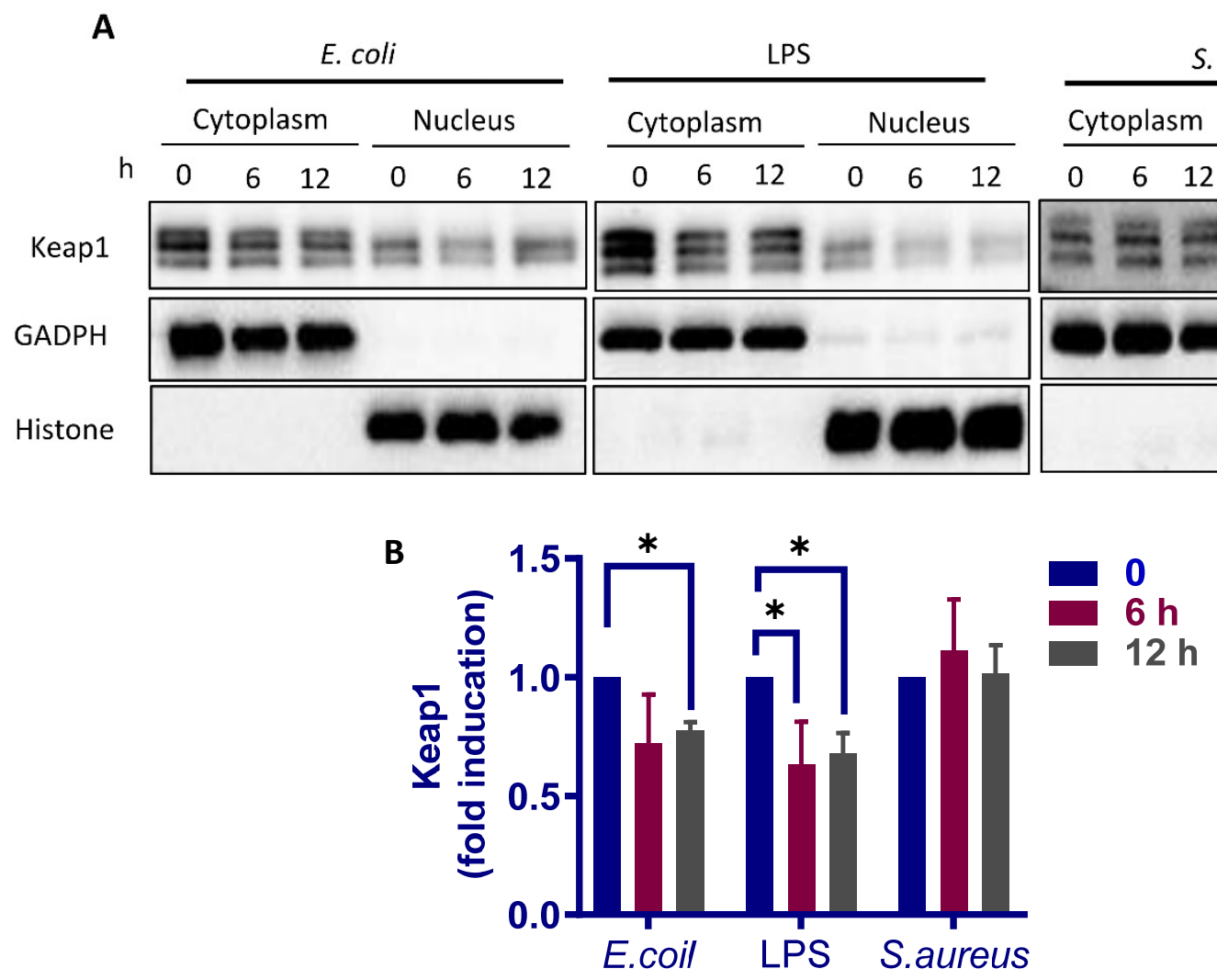

Figure 9. E. coli and S. aureus differentially regulate Keap1 degradation. (A) Cytoplasmic and nuclear proteins were extracted from cells treated with $E$. coli $\left(1 \times 10^{7}\right.$ particles $\left./ \mathrm{mL}\right)$, S. aureus $\left(1 \times 10^{7}\right.$ particles $\left./ \mathrm{mL}\right)$ and lipopolysaccharides (LPS) $(10 \mu \mathrm{g} / \mathrm{mL})$ and were analyzed by immunoblotting with anti-Keap1. GADPH and Histone are shown as loading controls, respectively. (B) A chart bar shows Keap1 levels determined with densitometry analyses after normalization to GADPH. Data are representative of three triplicates and are representative of 3 separate experiments. ${ }^{*} p<0.05$. 
A

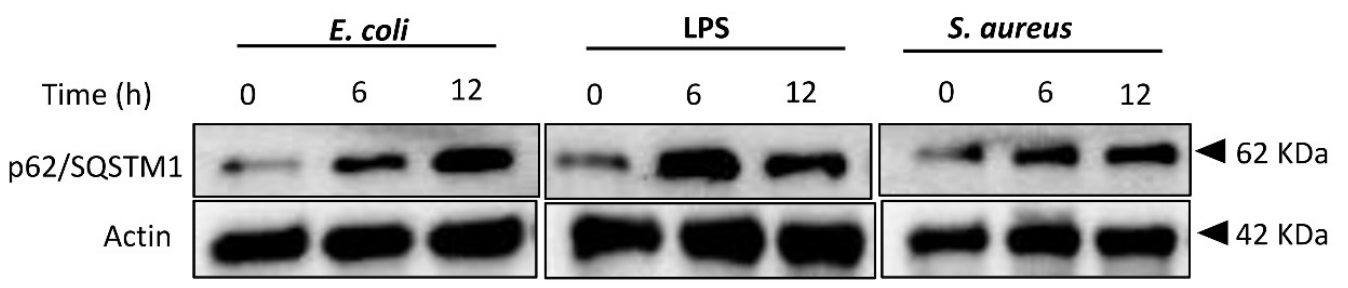

B
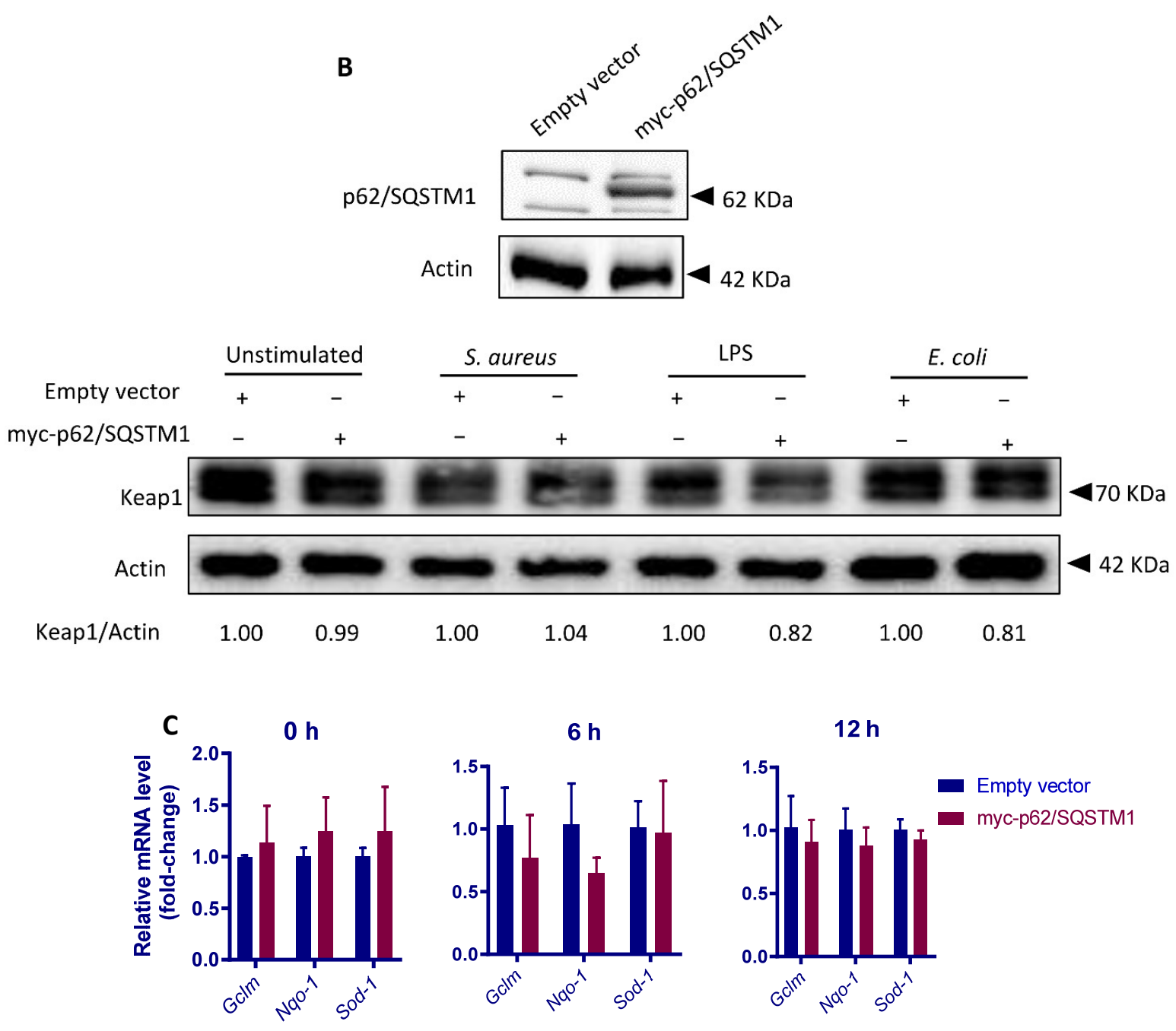

$6 \mathrm{~h}$

$12 \mathrm{~h}$
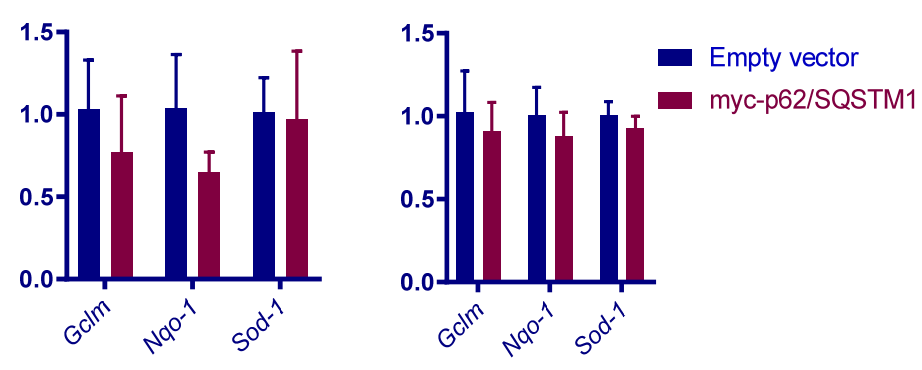

D

Time (h)
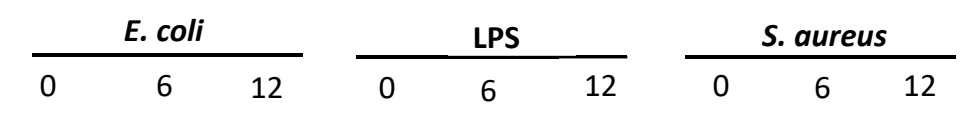

pSer349-p62/SQSTM1

Actin
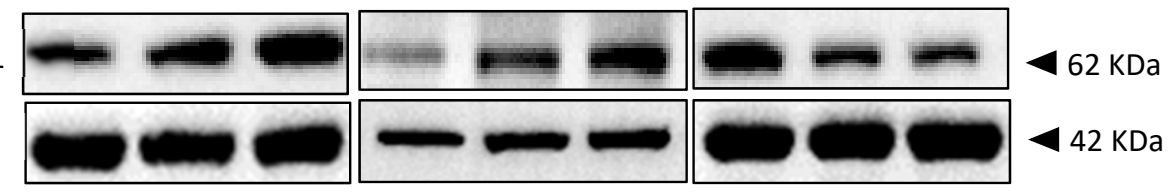

Figure 10. S. aureus and E. coli differentially modify p62/ SQSTM1 phosphorylation. (A) Evaluation of the p62/SQSTM1 protein levels in pbMECs. Cells were treated with heat-killed E. coli $\left(1 \times 10^{7}\right.$ particles $\left./ \mathrm{mL}\right), \mathrm{LPS}(10 \mu \mathrm{g} / \mathrm{mL}) \mathrm{or} S$. aureus $\left(1 \times 10^{7}\right.$ particles $\left./ \mathrm{mL}\right)$ for the indicate time. Whole-cell extracts were analysed by immunoblotting with anti-p62/SQSTM1. $\beta$-actin is shown as a loading control. The data are representative of 2 independent experiments. (B) Evaluation of the p62/SQSTM1-dependent Keap1 degradation. pbMECs were transfected with either mock (empty vector) or mycp62/SQSTM1 plasmid. Forty-eight hours post-transfection, the cells were treated heat-killed E. coli $\left(1 \times 10^{7}\right.$ particles $\left./ \mathrm{mL}\right)$, LPS $(10 \mu \mathrm{g} / \mathrm{mL})$ or S. aureus $\left(1 \times 10^{7}\right.$ particles $\left./ \mathrm{mL}\right)$ for a further $6 \mathrm{~h}$. Whole-cell extracts were analysed by immunoblotting 
with anti-Keap1. $\beta$-actin is shown as a loading control. The data are representative of 2 independent experiments. (C) Evaluation of Nrf2 activation in cells with p62/SQSTM1 overexpression in response to S. aureus. Mock-transfected and p62/SQSTM1 plasmid-transfected cells were treated as indicated above. Total mRNA was extracted and RT-qPCR was performed to measure the mRNA levels of Nrf2 target genes Ho-1, Glcm, Nqo-1, and Sod1. Data presented are the mean \pm s.d. of three triplicates and are representative of 3 separate experiments. (D) Evaluation of the effect of E. coli, S. aureus and LPS on phosphorylation of p62/SQSTM1 at Ser349 (pSer349-p62/SQSTM1). pbMECs were treated with heat-killed E. coli $\left(1 \times 10^{7}\right.$ particles $\left./ \mathrm{mL}\right)$, LPS $(10 \mu \mathrm{g} / \mathrm{mL})$ or S. aureus $\left(1 \times 10^{7}\right.$ particles $\left./ \mathrm{mL}\right)$ for the indicated time. Whole-cell extracts were analysed by immunoblotting with anti-pSer349-p62/SQSTM1. $\beta$-actin is shown as a loading control. The data are representative of 2 independent experiments.

\section{Discussion}

A number of studies have shown the different immune responses of the bovine mammary gland to distinct mastitis-causing pathogens $[9,25,46]$. Although the underlying molecular mechanisms are not fully understood, recent studies have repeatedly demonstrated that Gram-positive bacteria fail to activate pathogen receptor-derived activation of I $\mathrm{kB} / \mathrm{NF}-\kappa \mathrm{B}$ signaling as compared to Gram-negative bacteria [47,48]. Increasing evidence suggests that MECs in culture are able to model the key aspects of the immune response profile of pathogen species-specific mastitis $[20,49,50]$. Since it will take a longer time $(24 \mathrm{~h})$ for $S$. aureus than for $E$. coli to achieve the maximum impact on gene expression in host cells, and genes encoding cytokines and transcription regulators (e.g., NF- $\mathrm{kB}$ ) are constantly regulated by E. coli for $24 \mathrm{~h}$ [30], we challenged our pbMECs with E. coli and S. aureus, respectively, for $24 \mathrm{~h}$ before transcriptome analysis. Our data showed that challenging MECs with E. coli particles resulted in $>1400$ DEGs, while the $S$. aureus challenge altered the expression of only 16 genes. However, in another study, S. aureus challenge has been to shown to regulate more than 100 genes in pbMECs [30]. The discrepancy could be due to the difference in S. aureus strains investigated, since significant differences in host response to bovine-associated lineages have been previously reported [51]. E. coli induced the expression of a wealth of immune genes involved in inflammatory response signaling pathways such as the TLR signaling pathway, NOD-like receptor signaling pathway, and NF- $k B$ signaling pathway. On the contrary, none of these pathways were significantly affected by $S$. aureus particles. This is in agreement with other transcriptional profiling studies demonstrating that $E$. coli stimulation strongly upregulates the genes involved in the NF-kB pathway, whereas $S$. aureus does not $[21,30,47]$. Overall, our results support the notion that a lack of NF- $\mathrm{kB}$ activation accounts for the impaired immune response elicited by S. aureus [50].

Although extensively studied, the mechanisms through which S. aureus inhibits NF-kB activation in bovine mammary epithelial cells remains largely unclear. The Nrf2 signaling pathway plays a pivotal role in defense against oxidative stress and toxic insults and acts as a critical regulator of the innate immune response [37,52]. The distinct inflammatory response of pbMECs to E. coli and S. aureus led us to suggest that the Nrf2 pathway is differently regulated by the two pathogens. In support of this hypothesis, transcriptome differences revealed a distinct expression pattern of Nrf2 target genes in pbMECs challenged with E. coli and S. aureus, in that multiple Nrf2 target genes were induced by $E$. coli, while none of the genes dysregulated by S. aureus was linked to the Nrf2 pathway. In addition, Gene network analysis and KEGG pathway analysis results demonstrated that the upregulated Nrf2 target genes in response to E. coli particles are mainly involved in anti-oxidant and immune response. In accordance with the transcriptome analysis, Western blot analysis validated that $E$. coli was induced whereas S. aureus inhibited Nrf2 nuclear accumulation. No previous studies have evaluated the effect of $S$. aureus on Nrf2 induction in pbMECs. However, in a recent study, LPS has been shown to inhibit Nrf2 activation in Mac-T [53], a bovine mammary cell line obtained by stable transfection of mammary alveolar cells with simian virus-40 (SV-40) and large T-antigens [54]. Notably, there is a marked difference in the transcriptome signatures between mammary tissue and Mac-T 
cells [55], which might explain the difference in the Nrf2 response between pbMECs and Mac-T.

Several studies have demonstrated that Nrf2 produces an anti-inflammatory effect $[37,56,57]$. In stark contrast, the present study demonstrated that Nrf2 is indispensable for pbMECs to mount an efficient immune response. Supporting this notion is that Nrf2 knockdown significantly diminished LPS-induced NF- $\mathrm{KB}$ activation and transcription of pro-inflammatory cytokines. In support of our findings, Nrf2 is proved to positively regulate hepatic IL-6 expression [58] and NF-kB production [38]. Moreover, Nrf2 was found to be essential for cholesterol crystal-induced inflammasome activation and IL-1 production in vascular cells [59]. In a recent study, Nrf2 and NF- $k B$ are found to be regulated in the same direction in bovine granulosa cells during lead toxicity [60]. Thus, it appears that Nrf2 activation may enhance or attenuate inflammatory response, depending on the cell type/tissue context and stimuli. Considering the pro-inflammatory effect of Nrf2 in pbMECs, we could conclude that the weak inflammatory response of pbMECs to $S$. aureus is associated with impaired Nrf2 activation. Indeed, we did observe an enhanced transcription of pro-inflammatory cytokines in response to $S$. aureus in cells with Nrf2 overexpression.

Oxidative stress is a critical factor driving Nrf2 to detach from Keap1 and to subsequently translocate into the nucleus. Under basal conditions, Keap1 binds to the Neh2 domain of Nrf2 in the cytoplasm and targets Nrf2 for ubiquitination and proteasomal degradation. Upon oxidative stress, Nrf2 dissociates from Keap1 and translocates into the nucleus, where it transactivates several cytoprotective genes $[26,61,62]$. In the present study, we observed an ROS-dependent Nrf2 activation in pbMECs in response to LPS; in stark contrast, upon $S$. aureus challenge, pbMECs displayed increased intracellular ROS production but had reduced Nrf2 nuclear accumulation. Given that Nrf2 plays a major role in cellular defense against oxidative stress, and that $S$. aureus has the ability to encounter ROS [63], our results might explain why $S$. aureus infection usually causes severe damage in bovine udder tissue. In addition, a recent study has demonstrated that ROS produced by host cells coerce S. aureus into an antibiotic-tolerant state [64].

We next sought to clarify how S. aureus impairs Nrf2 activation. Although S. aureus produces a variety of proteins that can activate host zymogens targeting host components [65], we did not observe a direct impact of S. aureus on Nrf2 degradation by using a tBHQ-stimulated cell model. Indeed, we found that Keap1 protein was degraded in pbMECs in response to E. coli or LPS, but not following incubation with S. aureus, suggesting a high likelihood that $S$. aureus impairs Keap1 inactivation machinery. We next focused on p62/SQSTM1, a selective autophagy receptor that has been shown to play a central role in Nrf2 activation under oxidative stress through regulating autophagic degradation of Keap1 $[27,42,66]$. In agreement with a previous study $[67,68]$, we observed an increase in p62/SQSTM1 protein in response to $S$. aureus, resembling upregulation of p62/SQSTM1 protein following LPS or E. coli exposure. Taken together, the data suggest that $S$. aureus impairs p62/SQSTM1-mediated Keap1-degradation through autophagy. Indeed, in contrast to E. coli, we observed that $S$. aureus failed to induce Keap1 turnover even in cells bearing p62/SQSTM1-expressing plasmid. We next determined the level of Ser349-phosphorylated p62/SQSTM1, which has been previously shown to play a major role in p62/SQSTM1-Keap1 interaction through modulating the binding affinity of p62/SQSTM1 for Keap1 [27,45]. As expected, S. aureus challenge resulted in a marked reduction in Ser349-phosphorylated p62/SQSTM1. In contrast, LPS or E. coli stimulation had the opposite effect on phosphorylated p62/SQSTM1. Taken together, our results suggest that p62/SQSTM1-binding dependent Keap1 inactivation is impaired by $S$. aureus. The underlying mechanisms by which $S$. aureus manipulates p62/SQSTM1 phosphorylation remain unclear. Recent studies have suggested that TLR signaling is involved in p62/SQSTM1-mediated Keap1 reduction [44,69]. Given that E. coli strongly stimulates TLR pathway activation in MECs, whereas S. aureus induces only a slight transient activation of 
TLR2 [50], a linkage between dysregulated TLR signaling and impaired phosphorylation of Ser349 p62/SQSTM1 in S. aureus-stimulated cells could be suggested.

\section{Conclusions}

In summary, this work demonstrates a pathogen species-specific response of the Nrf2 pathway in bovine mammary epithelial cells. We show for the first time that $S$. aureus impairs Nrf2 activation as compared to E. coli and that Nrf2 overexpression could augment $S$. aureus-stimulated inflammatory response. We have also identified molecular mechanisms by which S. aureus impairs Nrf2 activation. It is suggested that impairment of Nrf2 activation contributes to the weak inflammatory response in S. aureus mastitis.

Supplementary Materials: The following are available online at https:/ / www.mdpi.com/article/10 .3390/cells10123426/s1, Figure S1: Enrichment map of Reactome pathways enriched in upregulated Nrf2 target genes; Figure S2: Determination of biologically relevant band of Nrf2 on SDS-PAGE gel; Nrf2 activation by LPS is ROS-dependent, Figure S3: Nrf2 activation by LPS is ROS-dependent; Figure S4: The effect of $S$. aureus on tBHQ-induced Nrf2 activation. Figure S5: The effect of tBHQ on the proinflammatory cytokine transcription in response to S. aureus. Table S1: Sequences of oligonucleotide primers used for real-time quantitative PCR analysis; Table S2: Dysregulated genes in response to S. aureus stimulation compared to unstimulated control cells; Table S3: Dysregulated Nrf2 downstream target genes in response to $E$. coli and S. aureus stimulation compared to unstimulated control cells; Additional file 1: Upregulated genes in response to E. coli demonstrated by RNA-seq; Additional file 2: Downregulated genes in response to E. coli demonstrated by RNA-seq.

Author Contributions: Conceptualization, X.T.; Methodology, Y.-T.Y. and X.T.; Formal Analysis, Y.-T.Y. and J.Y.; Data Curation, R.L., Y.Z., J.-X.X. and W.-J.R.; Writing-Original Draft Preparation, Y.-T.Y.; Writing-Review and Editing, Supervision, X.T.; Funding Acquisition, X.T. All authors have read and agreed to the published version of the manuscript.

Funding: This work was supported by the Zhejiang Provincial Key R \& D Program [Project No. 2020C02032], and the National Key R \& D Program of China [Project No. 2017YFD0502200].

Institutional Review Board Statement: The procedure was approved by the Animal Care and Use Committee guidelines in Zhejiang University (approval number ZJU20160379).

Informed Consent Statement: Not applicable.

Data Availability Statement: All data analyzed during this study are included in this published article and its Supplementary Information Flies.

Acknowledgments: We thank Undergraduate Experimental Teaching Centre of College of Animal Sciences, Zhejiang University, for assistance in qPCR analysis.

Conflicts of Interest: All authors declare no conflict of interest.

\section{References}

1. Sinha, M.K.; Thombare, N.N.; Mondal, B. Subclinical mastitis in dairy animals: Incidence, economics, and predisposing factors. Sci. World J. 2014, 2014, 523984. [CrossRef]

2. Bi, Y.; Wang, Y.J.; Qin, Y.; Guix, V.R.; Maldonado, G.J.; Sun, W.; Li, S.; Cao, Z. Prevalence of bovine mastitis pathogens in bulk tank milk in China. PLoS ONE 2016, 11, e155621. [CrossRef] [PubMed]

3. Schukken, Y.H.; Gunther, J.; Fitzpatrick, J.; Fontaine, M.C.; Goetze, L.; Holst, O.; Leigh, J.; Petzl, W.; Schuberth, H.J.; Sipka, A.; et al. Host-response patterns of intramammary infections in dairy cows. Vet. Immunol. Immunopathol. 2011, 144, 270-289. [CrossRef] [PubMed]

4. Tan, X.; Wei, L.J.; Fan, G.J.; Jiang, Y.N.; Yu, X.P. Effector responses of bovine blood neutrophils against Escherichia coli: Role of NOD1/NF-kappaB signalling pathway. Vet. Immunol. Immunopathol. 2015, 168, 68-76. [CrossRef] [PubMed]

5. Bouchard, D.S.; Rault, L.; Berkova, N.; Le Loir, Y.; Even, S. Inhibition of Staphylococcus aureus invasion into bovine mammary epithelial cells by contact with live Lactobacillus casei. Appl. Environ. Microbiol. 2013, 79, 877-885. [CrossRef]

6. Jensen, K.; Gunther, J.; Talbot, R.; Petzl, W.; Zerbe, H.; Schuberth, H.J.; Seyfert, H.M.; Glass, E.J. Escherichia coli- and Staphylococcus aureus-induced mastitis differentially modulate transcriptional responses in neighbouring uninfected bovine mammary gland quarters. BMC Genom. 2013, 14, 36. [CrossRef]

7. Almeida, R.A.; Dogan, B.; Klaessing, S.; Schukken, Y.H.; Oliver, S.P. Intracellular fate of strains of Escherichia coli isolated from dairy cows with acute or chronic mastitis. Vet. Res. Commun. 2011, 35, 89-101. [CrossRef] [PubMed] 
8. Almeida, R.A.; Matthews, K.R.; Cifrian, E.; Guidry, A.J.; Oliver, S.P. Staphylococcus aureus invasion of bovine mammary epithelial cells. J. Dairy Sci. 1996, 79, 1021-1026. [CrossRef]

9. Petzl, W.; Gunther, J.; Muhlbauer, K.; Seyfert, H.M.; Schuberth, H.J.; Hussen, J.; Sauter-Louis, C.; Hafner-Marx, A.; Zerbe, H. Early transcriptional events in the udder and teat after intra-mammary Escherichia coli and Staphylococcus aureus challenge. Innate Immun. 2016, 22, 294-304. [CrossRef] [PubMed]

10. Mcmillan, K.; Moore, S.C.; Mcauley, C.M.; Fegan, N.; Fox, E.M. Characterization of Staphylococcus aureus isolates from raw milk sources in Victoria, Australia. BMC Microbiol. 2016, 16, 169. [CrossRef]

11. Richardson, E.J.; Bacigalupe, R.; Harrison, E.M.; Weinert, L.A.; Lycett, S.; Vrieling, M.; Robb, K.; Hoskisson, P.A.; Holden, M.; Feil, E.J.; et al. Gene exchange drives the ecological success of a multi-host bacterial pathogen. Nat. Ecol. Evol. 2018, 2, 1468-1478. [CrossRef] [PubMed]

12. Yamamoto, M.; Kensler, T.W.; Motohashi, H. The KEAP1-NRF2 System: A Thiol-based sensor-effector apparatus for maintaining redox homeostasis. Physiol. Rev. 2018, 98, 1169-1203. [CrossRef] [PubMed]

13. Hayes, J.D.; Dinkova-Kostova, A.T. The Nrf2 regulatory network provides an interface between redox and intermediary metabolism. Trends Biochem. Sci. 2014, 39, 199-218. [CrossRef] [PubMed]

14. Ma, Q. Role of nrf2 in oxidative stress and toxicity. Annu. Rev. Pharmacol. Toxicol. 2013, 53, 401-426. [CrossRef]

15. Soares, M.P.; Ribeiro, A.M. Nrf2 as a master regulator of tissue damage control and disease tolerance to infection. Biochem. Soc. Trans. 2015, 43, 663-668. [CrossRef] [PubMed]

16. Yan, J.; Li, J.; Zhang, L.; Sun, Y.; Jiang, J.; Huang, Y.; Xu, H.; Jiang, H.; Hu, R. Nrf2 protects against acute lung injury and inflammation by modulating TLR4 and Akt signaling. Free Radic. Biol. Med. 2018, 121, 78-85. [CrossRef] [PubMed]

17. Gomez, J.C.; Dang, H.; Martin, J.R.; Doerschuk, C.M. Nrf2 modulates host defense during streptococcus pneumoniae pneumonia in mice. J. Immunol. 2016, 197, 2864-2879. [CrossRef]

18. Reddy, N.M.; Suryanarayana, V.; Kalvakolanu, D.V.; Yamamoto, M.; Kensler, T.W.; Hassoun, P.M.; Kleeberger, S.R.; Reddy, S.P. Innate immunity against bacterial infection following hyperoxia exposure is impaired in NRF2-deficient mice. J. Immunol. 2009, 183, 4601-4608. [CrossRef]

19. Capuco, A.V.; Wood, D.L.; Baldwin, R.; Mcleod, K.; Paape, M.J. Mammary cell number, proliferation, and apoptosis during a bovine lactation: Relation to milk production and effect of bST. J. Dairy Sci. 2001, 84, 2177-2187. [CrossRef]

20. Gunther, J.; Koy, M.; Berthold, A.; Schuberth, H.J.; Seyfert, H.M. Comparison of the pathogen species-specific immune response in udder derived cell types and their models. Vet. Res. 2016, 47, 22. [CrossRef] [PubMed]

21. Gilbert, F.B.; Cunha, P.; Jensen, K.; Glass, E.J.; Foucras, G.; Robert-Granie, C.; Rupp, R.; Rainard, P. Differential response of bovine mammary epithelial cells to Staphylococcus aureus or Escherichia coli agonists of the innate immune system. Vet. Res. 2013, 44, 40. [CrossRef]

22. Pareek, R.; Wellnitz, O.; Van Dorp, R.; Burton, J.; Kerr, D. Immunorelevant gene expression in LPS-challenged bovine mammary epithelial cells. J. Appl. Genet. 2005, 46, 171-177.

23. Porcherie, A.; Cunha, P.; Trotereau, A.; Roussel, P.; Gilbert, F.B.; Rainard, P.; Germon, P. Repertoire of Escherichia coli agonists sensed by innate immunity receptors of the bovine udder and mammary epithelial cells. Vet. Res. 2012, 43, 14. [CrossRef] [PubMed]

24. Bauer, I.; Gunther, J.; Wheeler, T.T.; Engelmann, S.; Seyfert, H.M. Extracellular milieu grossly alters pathogen-specific immune response of mammary epithelial cells. BMC Vet. Res. 2015, 11, 172. [CrossRef] [PubMed]

25. Petzl, W.; Zerbe, H.; Gunther, J.; Seyfert, H.M.; Hussen, J.; Schuberth, H.J. Pathogen-specific responses in the bovine udder. Models and immunoprophylactic concepts. Res. Vet. Sci. 2018, 116, 55-61. [CrossRef] [PubMed]

26. Zhang, D.D.; Hannink, M. Distinct cysteine residues in Keap1 are required for Keap1-dependent ubiquitination of Nrf2 and for stabilization of Nrf2 by chemopreventive agents and oxidative stress. Mol. Cell. Biol. 2003, 23, 8137-8151. [CrossRef] [PubMed]

27. Komatsu, M.; Kurokawa, H.; Waguri, S.; Taguchi, K.; Kobayashi, A.; Ichimura, Y.; Sou, Y.S.; Ueno, I.; Sakamoto, A.; Tong, K.I.; et al. The selective autophagy substrate p62 activates the stress responsive transcription factor Nrf2 through inactivation of Keap1. Nat. Cell Biol. 2010, 12, 213-223. [CrossRef] [PubMed]

28. Jedrzejczak, M.; Szatkowska, I. Bovine mammary epithelial cell cultures for the study of mammary gland functions. Vitro Cell. Dev. Biol. Anim. 2014, 50, 389-398. [CrossRef]

29. Pal, K.; Grover, P.L. A simple method for the removal of contaminating fibroblasts from cultures of rat mammary epithelial cells. Cell Biol. Int. Rep. 1983, 7, 779-783. [CrossRef]

30. Gunther, J.; Esch, K.; Poschadel, N.; Petzl, W.; Zerbe, H.; Mitterhuemer, S.; Blum, H.; Seyfert, H.M. Comparative kinetics of Escherichia coli- and Staphylococcus aureus-specific activation of key immune pathways in mammary epithelial cells demonstrates that $S$. aureus elicits a delayed response dominated by interleukin-6 (IL-6) but not by IL-1A or tumor necrosis factor alpha. Infect. Immun. 2011, 79, 695-707.

31. Pfaffl, M.W. A new mathematical model for relative quantification in real-time RT-PCR. Nucleic Acids Res. 2001, 29, e45. [CrossRef]

32. Bryan, H.K.; Olayanju, A.; Goldring, C.E.; Park, B.K. The Nrf2 cell defence pathway: Keap1-dependent and -independent mechanisms of regulation. Biochem. Pharmacol. 2013, 85, 705-717. [CrossRef]

33. Fabregat, A.; Jupe, S.; Matthews, L.; Sidiropoulos, K.; Gillespie, M.; Garapati, P.; Haw, R.; Jassal, B.; Korninger, F.; May, B.; et al. The reactome pathway knowledgebase. Nucleic Acids Res. 2018, 46, D649-D655. [CrossRef] 
34. Rushworth, S.A.; Macewan, D.J.; O'Connell, M.A. Lipopolysaccharide-induced expression of NAD(P)H:quinone oxidoreductase 1 and heme oxygenase-1 protects against excessive inflammatory responses in human monocytes. J. Immunol. 2008, 181, 6730-6737. [CrossRef]

35. Lau, A.; Tian, W.; Whitman, S.A.; Zhang, D.D. The predicted molecular weight of Nrf2: It is what it is not. Antioxid. Redox Signal. 2013, 18, 91-93. [CrossRef]

36. Nguyen, T.; Sherratt, P.J.; Nioi, P.; Yang, C.S.; Pickett, C.B. Nrf2 controls constitutive and inducible expression of ARE-driven genes through a dynamic pathway involving nucleocytoplasmic shuttling by Keap1. J. Biol. Chem. 2005, 280, 32485-32492. [CrossRef]

37. Kobayashi, E.H.; Suzuki, T.; Funayama, R.; Nagashima, T.; Hayashi, M.; Sekine, H.; Tanaka, N.; Moriguchi, T.; Motohashi, H.; Nakayama, K.; et al. Nrf2 suppresses macrophage inflammatory response by blocking proinflammatory cytokine transcription. Nat. Commun. 2016, 7, 11624. [CrossRef]

38. Yang, H.; Magilnick, N.; Lee, C.; Kalmaz, D.; Ou, X.; Chan, J.Y.; Lu, S.C. Nrf1 and Nrf2 regulate rat glutamate-cysteine ligase catalytic subunit transcription indirectly via NF-kappaB and AP-1. Mol. Cell. Biol. 2005, 25, 5933-5946. [CrossRef]

39. Zhang, X.; Chen, X.; Song, H.; Chen, H.Z.; Rovin, B.H. Activation of the Nrf2/antioxidant response pathway increases IL-8 expression. Eur. J. Immunol. 2005, 35, 3258-3267. [CrossRef] [PubMed]

40. Abiko, Y.; Miura, T.; Phuc, B.H.; Shinkai, Y.; Kumagai, Y. Participation of covalent modification of Keap1 in the activation of Nrf2 by tert-butylbenzoquinone, an electrophilic metabolite of butylated hydroxyanisole. Toxicol. Appl. Pharmacol. 2011, 255, 32-39. [CrossRef]

41. Mcmahon, M.; Lamont, D.J.; Beattie, K.A.; Hayes, J.D. Keap1 perceives stress via three sensors for the endogenous signaling molecules nitric oxide, zinc, and alkenals. Proc. Natl. Acad. Sci. USA 2010, 107, 18838-18843. [CrossRef]

42. Lau, A.; Wang, X.J.; Zhao, F.; Villeneuve, N.F.; Wu, T.; Jiang, T.; Sun, Z.; White, E.; Zhang, D.D. A noncanonical mechanism of Nrf2 activation by autophagy deficiency: Direct interaction between Keap1 and p62. Mol. Cell. Biol. 2010, 30, 3275-3285. [CrossRef]

43. Silva-Islas, C.A.; Maldonado, P.D. Canonical and non-canonical mechanisms of Nrf2 activation. Pharmacol. Res. 2018, 134, 92-99. [CrossRef]

44. Yin, S.; Cao, W. Toll-like receptor signaling induces nrf2 pathway activation through p62-triggered keap1 degradation. Mol. Cell. Biol. 2015, 35, 2673-2683. [CrossRef]

45. Ichimura, Y.; Waguri, S.; Sou, Y.S.; Kageyama, S.; Hasegawa, J.; Ishimura, R.; Saito, T.; Yang, Y.; Kouno, T.; Fukutomi, T.; et al Phosphorylation of p62 activates the Keap1-Nrf2 pathway during selective autophagy. Mol. Cell 2013, 51, 618-631. [CrossRef]

46. Bannerman, D.D.; Paape, M.J.; Lee, J.W.; Zhao, X.; Hope, J.C.; Rainard, P. Escherichia coli and Staphylococcus aureus elicit differential innate immune responses following intramammary infection. Clin. Diagn. Lab. Immunol. 2004, 11, 463-472. [CrossRef]

47. Gunther, J.; Petzl, W.; Bauer, I.; Ponsuksili, S.; Zerbe, H.; Schuberth, H.J.; Brunner, R.M.; Seyfert, H.M. Differentiating Staphylococcus aureus from Escherichia coli mastitis: S. aureus triggers unbalanced immune-dampening and host cell invasion immediately after udder infection. Sci. Rep. 2017, 7, 4811. [CrossRef]

48. Petzl, W.; Zerbe, H.; Gunther, J.; Yang, W.; Seyfert, H.M.; Nurnberg, G.; Schuberth, H.J. Escherichia coli, but not Staphylococcus aureus triggers an early increased expression of factors contributing to the innate immune defense in the udder of the cow. Vet. Res. 2008, 39, 18. [CrossRef]

49. Strandberg, Y.; Gray, C.; Vuocolo, T.; Donaldson, L.; Broadway, M.; Tellam, R. Lipopolysaccharide and lipoteichoic acid induce different innate immune responses in bovine mammary epithelial cells. Cytokine 2005, 31, 72-86. [CrossRef] [PubMed]

50. Fu, Y.; Zhou, E.; Liu, Z.; Li, F.; Liang, D.; Liu, B.; Song, X.; Zhao, F.; Fen, X.; Li, D.; et al. Staphylococcus aureus and Escherichia coli elicit different innate immune responses from bovine mammary epithelial cells. Vet. Immunol. Immunopathol. 2013, 155, $245-252$. [CrossRef]

51. Murphy, M.P.; Niedziela, D.A.; Leonard, F.C.; Keane, O.M. The in vitro host cell immune response to bovine-adapted Staphylococcus aureus varies according to bacterial lineage. Sci. Rep. 2019, 9, 6134. [CrossRef]

52. Thimmulappa, R.K.; Lee, H.; Rangasamy, T.; Reddy, S.P.; Yamamoto, M.; Kensler, T.W.; Biswal, S. Nrf2 is a critical regulator of the innate immune response and survival during experimental sepsis. J. Clin. Investig. 2006, 116, 984-995. [CrossRef] [PubMed]

53. Fusco, R.; Cordaro, M.; Siracusa, R.; Peritore, A.F.; D'Amico, R.; Licata, P.; Crupi, R.; Gugliandolo, E. Effects of hydroxytyrosol against lipopolysaccharide-induced inflammation and oxidative stress in bovine mammary epithelial cells: A Natural Therapeutic Tool for Bovine Mastitis. Antioxidants 2020, 9, 693. [CrossRef]

54. Huynh, H.T.; Robitaille, G.; Turner, J.D. Establishment of bovine mammary epithelial cells (MAC-T): An in vitro model for bovine lactation. Exp. Cell Res. 1991, 197, 191-199. [CrossRef]

55. Hosseini, A.; Rekha, S.; Bionaz, M.; Loor, J.J. Transcriptomics comparisons of mac-t cells versus mammary tissue during late pregnancy and peak lactation. Adv. Dairy Res. 2013, 1, 103.

56. Boyanapalli, S.S.; Paredes-Gonzalez, X.; Fuentes, F.; Zhang, C.; Guo, Y.; Pung, D.; Saw, C.L.; Kong, A.N. Nrf2 knockout attenuates the anti-inflammatory effects of phenethyl isothiocyanate and curcumin. Chem. Res. Toxicol. 2014, 27, 2036-2043. [CrossRef]

57. Kong, X.; Thimmulappa, R.; Craciun, F.; Harvey, C.; Singh, A.; Kombairaju, P.; Reddy, S.P.; Remick, D.; Biswal, S. Enhancing Nrf2 pathway by disruption of Keap1 in myeloid leukocytes protects against sepsis. Am. J. Respir. Crit. Care Med. 2011, 184, 928-938. [CrossRef] 
58. Wruck, C.J.; Streetz, K.; Pavic, G.; Gotz, M.E.; Tohidnezhad, M.; Brandenburg, L.O.; Varoga, D.; Eickelberg, O.; Herdegen, T.; Trautwein, C.; et al. Nrf2 induces interleukin-6 (IL-6) expression via an antioxidant response element within the IL-6 promoter. J. Biol. Chem. 2011, 286, 4493-4499. [CrossRef]

59. Freigang, S.; Ampenberger, F.; Spohn, G.; Heer, S.; Shamshiev, A.T.; Kisielow, J.; Hersberger, M.; Yamamoto, M.; Bachmann, M.F.; Kopf, M. Nrf2 is essential for cholesterol crystal-induced inflammasome activation and exacerbation of atherosclerosis. Eur. J. Immunol. 2011, 41, 2040-2051. [CrossRef] [PubMed]

60. Aglan, H.S.; Gebremedhn, S.; Salilew-Wondim, D.; Neuhof, C.; Tholen, E.; Holker, M.; Schellander, K.; Tesfaye, D. Regulation of Nrf2 and NF-kappaB during lead toxicity in bovine granulosa cells. Cell Tissue Res. 2020, 380, 643-655. [CrossRef] [PubMed]

61. Espinosa-Diez, C.; Miguel, V.; Mennerich, D.; Kietzmann, T.; Sanchez-Perez, P.; Cadenas, S.; Lamas, S. Antioxidant responses and cellular adjustments to oxidative stress. Redox Biol. 2015, 6, 183-197. [CrossRef]

62. Kobayashi, A.; Kang, M.I.; Okawa, H.; Ohtsuji, M.; Zenke, Y.; Chiba, T.; Igarashi, K.; Yamamoto, M. Oxidative stress sensor Keap1 functions as an adaptor for Cul3-based E3 ligase to regulate proteasomal degradation of Nrf2. Mol. Cell. Biol. 2004, 24, 7130-7139. [CrossRef] [PubMed]

63. Rushworth, S.A.; Shah, S.; Macewan, D.J. TNF mediates the sustained activation of Nrf2 in human monocytes. J. Immunol. 2011, 187, 702-707. [CrossRef] [PubMed]

64. Rowe, S.E.; Wagner, N.J.; Li, L.; Beam, J.E.; Wilkinson, A.D.; Radlinski, L.C.; Zhang, Q.; Miao, E.A.; Conlon, B.P. Reactive oxygen species induce antibiotic tolerance during systemic Staphylococcus aureus infection. Nat. Microbiol. 2020, 5, 282-290. [CrossRef]

65. Pietrocola, G.; Nobile, G.; Rindi, S.; Speziale, P. Staphylococcus aureus manipulates innate immunity through own and hostexpressed proteases. Front. Cell Infect. Microbiol. 2017, 7, 166. [CrossRef] [PubMed]

66. Hayashi, K.; Dan, K.; Goto, F.; Tshuchihashi, N.; Nomura, Y.; Fujioka, M.; Kanzaki, S.; Ogawa, K. The autophagy pathway maintained signaling crosstalk with the Keap1-Nrf2 system through p62 in auditory cells under oxidative stress. Cell. Signal. 2015, 27, 382-393. [CrossRef] [PubMed]

67. Wang, H.; Zhou, Y.; Zhu, Q.; Zang, H.; Cai, J.; Wang, J.; Cui, L.; Meng, X.; Zhu, G.; Li, J. Staphylococcus aureus induces autophagy in bovine mammary epithelial cells and the formation of autophagosomes facilitates intracellular replication of Staph. aureus. J. Dairy Sci. 2019, 102, 8264-8272. [CrossRef] [PubMed]

68. Zhong, Z.; Umemura, A.; Sanchez-Lopez, E.; Liang, S.; Shalapour, S.; Wong, J.; He, F.; Boassa, D.; Perkins, G.; Ali, S.R.; et al. NF-kappaB restricts inflammasome activation via elimination of damaged mitochondria. Cell 2016, 164, 896-910. [CrossRef] [PubMed]

69. Deng, S.; Yu, K.; Jiang, W.; Li, Y.; Wang, S.; Deng, Z.; Yao, Y.; Zhang, B.; Liu, G.; Liu, Y.; et al. Over-expression of Toll-like receptor 2 up-regulates heme oxygenase-1 expression and decreases oxidative injury in dairy goats. J. Anim. Sci. Biotechnol. 2017, 8, 3. [CrossRef] [PubMed] 